\title{
Does my dizzy patient have a stroke? A systematic review of bedside diagnosis in acute vestibular syndrome
}

\author{
Alexander A. Tarnutzer MD, Aaron L. Berkowitz MD PhD, Karen A. Robinson PhD, Yu-Hsiang Hsieh PhD, \\ David E. Newman-Toker MD PhD
}

$\mathrm{D}$ izziness is the third most common major medical symptom reported in general medical clinics ${ }^{1}$ and accounts for about $3 \%-5 \%$ of visits across care settings. ${ }^{2}$ In the United States, this translates to 10 million ambulatory visits per year because of dizziness, ${ }^{3}$ with roughly $25 \%$ of these visits to emergency departments. ${ }^{2}$ Many patients have transient or episodic symptoms that last seconds, minutes or hours, but some have prolonged dizziness that persists continuously for days to weeks. ${ }^{4}$

In this article, we use the term "dizziness" to encompass vertigo, presyncope, unsteadiness, and other nonspecific forms of dizziness. When dizziness develops acutely, is accompanied by nausea or vomiting, unsteady gait, nystagmus and intolerance to head motion, and persists for a day or more, the clinical condition is known as acute vestibular syndrome. ${ }^{5,6} \mathrm{We}$ define isolated acute vestibular syndrome (with or without hearing loss) as occurring in the absence of focal neurologic signs such as hemiparesis, hemisensory loss or gaze palsy. Transient dizziness has a differential diagnosis distinct from that of acute vestibular syndrome, and the approach to diagnosis should differ accordingly. ${ }^{7}$ In this review, we focus on acute vestibular syndrome, whether isolated or not.

Most patients with acute vestibular syndrome have an acute, benign, self-limited condition presumed to be viral or postviral. The condition is usually called vestibular neuritis but is sometimes referred to as vestibular neuronitis, laby rinthitis, neurolabyrinthitis or acute peripheral vestibulopathy. ${ }^{5,6}$ Some authors distinguish between labyrinthitis and vestibular neuritis based on the presence of auditory symptoms at presentation; ${ }^{8}$ however, this distinction is inconsistently applied, and the terms are often used interchangeably. In this article, we include labyrinthitis and vestibular neuritis together as peripheral causes of acute vestibular syndrome - that is, pathology localized to the inner ear (labyrinth) or eighth cranial (vestibular) nerve - as distinguished from central causes affecting vestibular connections in the central nervous system. Al- though peripheral causes are more common, dangerous central causes, particularly ischemic stroke in the brainstem or cerebellum, can mimic benign peripheral causes closely. ${ }^{6,-13}$

The evidence base for diagnosing the cause of dizziness is limited. ${ }^{14}$ There is growing evidence that the cause of acute vestibular syndrome is misdiagnosed in many patients ${ }^{15-19}$ and that frontline physicians are eager for diagnostic guidelines. ${ }^{20,21}$ Regional variation in diagnostic practice is probably common, ${ }^{3}$ but little is known about factors influencing diagnostic accuracy (e.g., access to technology, availability of consultants, nature of training, cultural or linguistic differences).

Narrative reviews have highlighted the importance of accurately assessing the risk of dangerous disorders, particularly ischemic stroke in the posterior fossa, and have emphasized the utility of a focused history and physical examination in these patients. ${ }^{522-24}$ However, we are unaware of any systematic reviews, practice parameters or fully validated clinical decision rules applicable to unselected patients with acute, prolonged dizziness that offer evidence-based guidance for the diagnosis and management of acute vestibular syndrome. We therefore performed a systematic review and synthesis of the medical literature, focusing on bedside diagnostic predictors.

\section{KEY POINTS}

- The most common causes of acute vestibular syndrome are vestibular neuritis (often called labyrinthitis) and ischemic stroke in the brainstem or cerebellum.

- Vertebrobasilar ischemic stroke may closely mimic peripheral vestibular disorders, with obvious focal neurologic signs absent in more than half of people presenting with acute vestibular syndrome due to stroke.

- Computed tomography has poor sensitivity in acute stroke, and diffusion-weighted magnetic resonance imaging (MRI) misses up to one in five strokes in the posterior fossa in the first 24-48 hours.

- Expert opinion suggests a combination of focused history and physical examination as the initial approach to evaluating whether acute vestibular syndrome is due to stroke.

- A three-component bedside oculomotor examination - HINTS (horizontal head impulse test, nystagmus and test of skew) — identifies stroke with high sensitivity and specificity in patients with acute vestibular syndrome and rules out stroke more effectively than early diffusion-weighted MRI. 


\section{Literature review and analysis}

Details of the search strategy appear in Appendix 1. In brief, we searched MEDLINE to identify English-language observational studies on the clin-

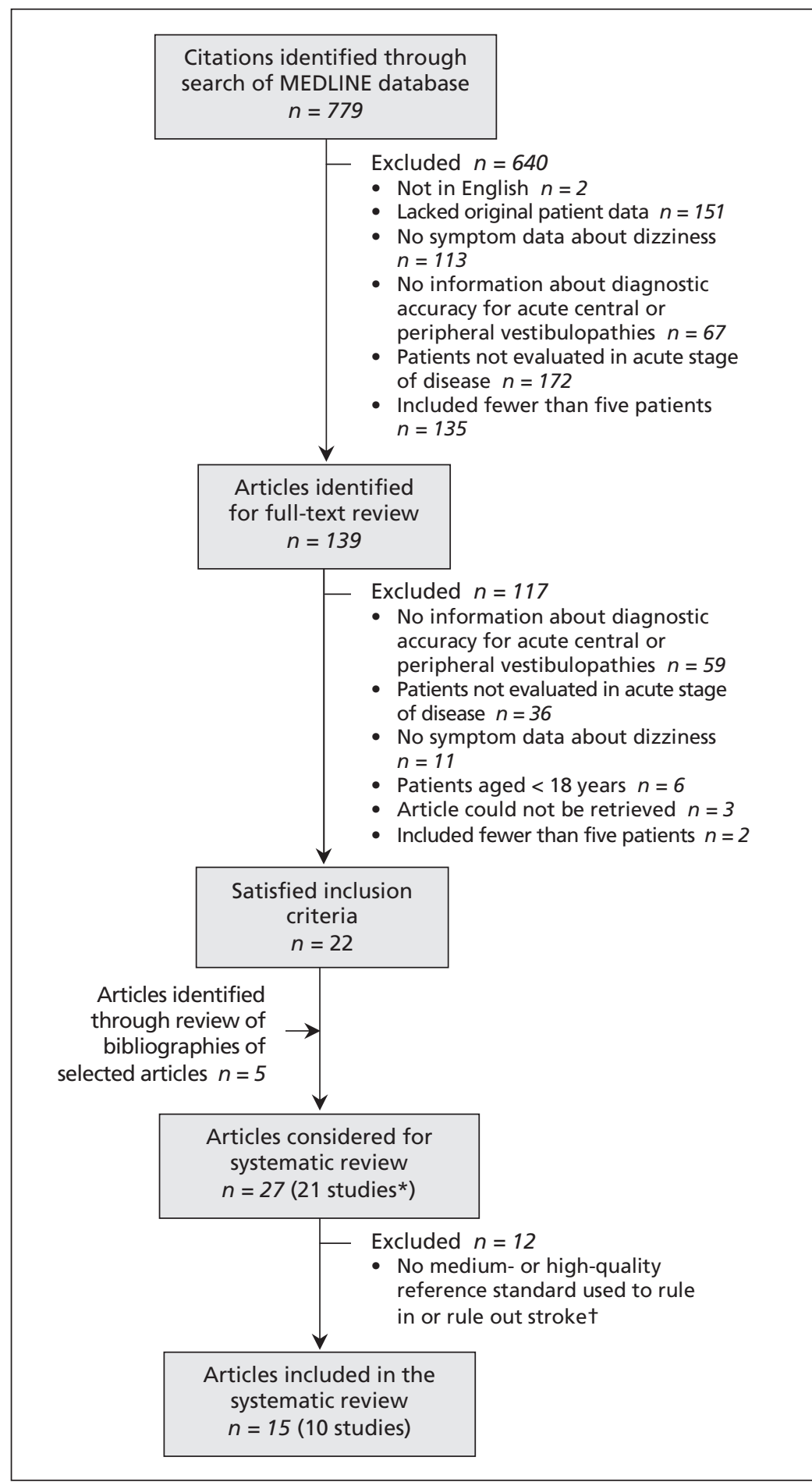

Figure 1: Flow diagram indicating selection of articles. *In two articles ${ }^{26,27}$ ( $n=$ 108), published by a single research group, it is unclear whether each article reports on an entirely distinct or partially overlapping group of patients (see Table 1 for details). There could be as many as 28 patients counted more than once. TThe criteria used to assess the strength of the reference standards used to rule in or rule out stroke appear in Appendix 1. ical features, diagnostic evaluation and differential diagnosis of acute vestibular syndrome published through Dec. 4, 2009. We also performed a manual search of the bibliographies of eligible articles.

Titles and abstracts of identified articles were screened independently by two reviewers (A.A.T. and A.L.B.). Articles were excluded if they lacked original patient data, offered no symptom data about dizziness, provided no information about diagnostic accuracy for acute central or peripheral vestibulopathies, did not evaluate patients in the acute stage of disease, involved patients under age 18 years or reported on fewer than five patients. Full-text versions of eligible articles were reviewed independently by the same two reviewers. A third reviewer (D.N.T.) verified the eligibility of selected articles and settled any discrepancies.

One unmasked rater (A.A.T.) assessed the strength of the reference standards used in the included studies to distinguish between a peripheral and a central cause of acute vestibular syndrome. A second unmasked rater (D.N.-T.) verified the strength of the reference standard. (Definitions of the criteria used to assess the strength of the reference standards appear in Appendix 1.)

Information abstracted from each article included study type, number of patients with dizziness, inclusion criteria and study site. Also extracted were data on the diagnostic tests used and the proportion of patients with positive or negative test results. Where appropriate, we attempted to contact authors regarding study details.

For each test that was used in two or more studies, we calculated the pooled sensitivity, specificity, and positive and negative likelihood ratios (and 95\% confidence intervals [CIs]) for the test. ${ }^{25}$ No formal tests of heterogeneity were applied, but we conducted a prospectively defined subgroup analysis that compared findings in stroke patients who had an infarction in the territory of the anterior inferior cerebellar artery with findings in those who had cerebellar infarctions in other vascular territories (posterior inferior cerebellar artery or superior cerebellar artery). All $p$ values were twosided, with significance set at $p<0.05$.

In instances where evidence derived from our systematic review was incomplete, we included expert opinion and critically reviewed related evidence to support or refute such opinion. Evidence failing to meet strict inclusion criteria was considered part of the critical review.

Details of the results of our literature search appear in Appendix 1 and Figure 1. Our systematic search identified 779 unique citations. We reviewed 139 full-text articles and their bibliographies and found 27 articles reporting data from 21 studies that met the inclusion criteria. 
We excluded 12 articles reporting data from 11 studies because of inadequate diagnostic reference standards, which left 10 studies describing a total of 392 patients. Details of these studies appear in Table 1.

\section{How common is acute vestibular syndrome?}

We found no direct studies of the incidence of acute vestibular syndrome as a clinical presentation. Vestibular neuritis, probably the most common cause of acute vestibular syndrome, has an estimated annual incidence of 3.5 per 100000 population based on a single retrospective survey of neuro-otology clinics in Japan. ${ }^{36}$ Data from a nationally representative sample of emergency departments in the United States indicate that, of 2.6 million visits annually because of dizziness, acute vestibular syndrome from a peripheral cause (i.e., vestibular neuritis or labyrinthitis) is diagnosed in $6 \%$ of patients, which corresponds to about 150000 visits each year. ${ }^{2,18}$ Another 4\% of patients receive a cerebrovascular diagnosis, and $22 \%$ leave the emergency department without a causal diagnosis (i.e., they receive a diagnosis of "dizziness or vertigo"), ${ }^{2,18}$ many of whom probably presented with acute vestibular syndrome. From a survey of the general population in Germany, $11 \%$ of those who reported dizziness indicated that the symptom had lasted for more than a day. ${ }^{4}$ In a US-based study involving consecutive patients who visited an emergency department because of dizziness, ${ }^{37}$ $27 \%(47 / 175)$ of those who had any dizziness in the 24 hours before their visit still had dizziness in the emergency department that had not remitted since it began (unpublished data). Thus, we estimate that about $10 \%$ to $20 \%$ of patients who present with acute dizziness to the emergency department have acute vestibular syndrome, which corresponds to about 250000 to 500000 visits to an emergency department each year in the United States alone.

\section{What are the most common causes?}

In our systematic review, we found no studies of all presentations of acute vestibular syndrome. Only three studies enrolled relatively unselected, consecutive populations. ${ }^{6,911}$ Vestibular neuritis was the most common peripheral cause of acute vestibular syndrome, and there were no patients with labrynthitis (i.e., peripheral cause of acute vestibular syndrome with auditory symptoms) reported in these studies. However, two studies expressly excluded patients with auditory symptoms, ${ }^{9,11}$ and the third excluded patients with a history of recurrent auditory symptoms. ${ }^{6}$

The most common central causes of acute vestibular syndrome reported in these three studies are listed in Table 2. Central causes mimicking vestibular neuritis (sometimes called "pseudoneuritis" ${ }^{11}$ ) were predominantly cerebrovascular $(83 \%)$ and demyelinating conditions $(11 \%)$. Two studies prospectively enrolled patients at high risk for stroke using age or vascular risk factors as entry criteria, ${ }^{6,9}$ which probably led to overrepresentation of cerebrovascular patients; the third study used a case-control design and did not report the method for sampling patients in the control group. ${ }^{11}$ The remaining seven studies included in the systematic review focused only on patients with acute dizziness who had a diagnosis of stroke. ${ }^{10,26-28,31-33}$

None of the included studies was large enough to identify rare but important causes such as Wernicke syndrome, ${ }^{38}$ bacterial labyrinthitis ${ }^{39}$ or brainstem encephalitis. ${ }^{40}$ Box 1 shows a suggested differential diagnosis for acute vestibular syndrome adapted from narrative reviews written by specialists in the field of vestibular disorders. ${ }^{8,24}$

Findings from our systematic review do not allow a definitive statement about the relative prevalence of vestibular neuritis versus stroke among unselected patients presenting with acute vestibular syndrome. We can, however, roughly estimate the proportion of patients presenting with acute vestibular syndrome who have stroke, using data on the annual incidence of stroke and prevalence of dizziness among stroke patients. Of 795000 strokes per year in the United States ${ }^{45}$ about $18 \%$ are located in the posterior fossa ${ }^{46}$ and about $50 \%-70 \%$ are associated with dizziness as a prominent or presenting symptom. ${ }^{22,47}$ Thus, we estimate that there are about 70000 to 100000 strokes per year in the United States with dizziness as a prominent or presenting symptom. Considering the approximate incidence of acute vestibular syndrome calculated earlier (about 250000 to 500000 per year in the United States), we estimate the true proportion of acute vestibular syndrome due to stroke to be about $25 \% \pm 15 \%$.

\section{What elements of clinical history are useful for diagnosis?}

Certain clinical findings from history-taking help to distinguish between stroke and vestibular neuritis in patients presenting with acute vestibular 
Table 1: Characteristics of studies included in the systematic review of bedside diagnostic predictors of stroke in patients with acute vestibular syndrome (AVS)

\begin{tabular}{|c|c|c|c|c|c|c|c|}
\hline Study & $\begin{array}{l}\text { No. of patients } \\
\text { screened } \\
\text { (no. included } \\
\text { in study) }\end{array}$ & $\begin{array}{l}\text { Study population } \\
\text { (study focus) }\end{array}$ & $\begin{array}{l}\text { Study } \\
\text { site }\end{array}$ & $\begin{array}{l}\text { Diagnostic } \\
\text { reference } \\
\text { standards }\end{array}$ & $\begin{array}{l}\text { Strength of } \\
\text { reference } \\
\text { standard to } \\
\text { rule in/rule out } \\
\text { stroke* }\end{array}$ & Study design & Comments \\
\hline $\begin{array}{l}\text { Rubenstein } \\
\text { et al. }^{28}\end{array}$ & $7 \quad(7)$ & $\begin{array}{l}\text { AVS and diagnosis of } \\
\text { cerebellar stroke or } \\
\text { hemorrhage (clinical } \\
\text { findings) }\end{array}$ & NR & $\begin{array}{l}\text { - CT (all } \\
\text { patients) }\end{array}$ & Medium/NA & $\begin{array}{l}\text { Retrospective } \\
\text { case series }\end{array}$ & $\begin{array}{l}\text { Clinical evaluation delayed } \\
\text { relative to onset of symptoms } \\
\text { up to } 7 \mathrm{~d} \text {. }\end{array}$ \\
\hline $\begin{array}{l}\text { Norrving et al. }{ }^{9} \\
\text { (preliminary } \\
\text { report in } \\
\text { Magnusson } \\
\text { et al. } .^{2,30} \text { ) }\end{array}$ & $24 \quad(24)$ & $\begin{array}{l}\text { AVS for }>48 \mathrm{~h} \text { and } \\
\text { age } 50-75 \mathrm{yr} \text { (clinical } \\
\text { findings and electro- } \\
\text { oculography) }\end{array}$ & $\mathrm{ED} / \mathrm{HA}$ & $\begin{array}{l}\text { - MRI without } \\
\text { DWI }(n=22) \\
\text { - CT }(n=2)\end{array}$ & $\begin{array}{l}\text { Medium/ } \\
\text { Medium }\end{array}$ & $\begin{array}{l}\text { Prospective } \\
\text { cross-sectional } \\
\text { study } \\
\text { (consecutive } \\
\text { cases) }\end{array}$ & $\begin{array}{l}\text { Only } 4 \text { patients had CT in acute } \\
\text { phase; MRI was performed 14- } \\
44 \mathrm{~d} \text { after onset of symptoms. } \\
\text { Patients with brainstem/ } \\
\text { cerebellar dysfunction other } \\
\text { than nystagmus were excluded. }\end{array}$ \\
\hline Kim et al..$^{31}$ & $30 \quad(30)$ & $\begin{array}{l}\text { Acute isolated vertigo } \\
\text { and diagnosis of stroke } \\
\text { (clinical findings) }\end{array}$ & ED/HA & $\begin{array}{l}\text { - MRI without } \\
\text { DWI }(n=17) \\
\text { - CT }(n=13)\end{array}$ & Medium/NA & $\begin{array}{l}\text { Prospective case } \\
\text { series (possibly } \\
\text { consecutive) }\end{array}$ & $\begin{array}{l}\text { CT obtained in all patients. MRI } \\
\text { obtained in those with initially } \\
\text { negative CT. }\end{array}$ \\
\hline Chen et al. ${ }^{32}$ & $295 \quad(7)$ & $\begin{array}{l}\text { Acute vertigo and } \\
\text { diagnosis of brainstem } \\
\text { stroke (clinical findings, } \\
\text { caloric testing and } \\
\text { vestibular-evoked } \\
\text { myogenic potentials) }\end{array}$ & $\mathrm{ED} / \mathrm{HA}$ & $\begin{array}{l}\text { - MRI without } \\
\text { DWI (all } \\
\text { patients) }\end{array}$ & Medium/NA & $\begin{array}{l}\text { Retrospective } \\
\text { case series } \\
\text { (possibly } \\
\text { consecutive) }\end{array}$ & $\begin{array}{l}\text { Unclear whether patients with } \\
\text { cerebellar infarctions were } \\
\text { considered or included. }\end{array}$ \\
\hline Lee et $a{ }^{26}{ }^{26} \dagger$ & $28 \quad(28)$ & $\begin{array}{l}\text { Acute audiovestibular } \\
\text { loss and diagnosis of } \\
\text { vertebrobasilar } \\
\text { infarction (clinical } \\
\text { findings and audiometric } \\
\text { assessment) }\end{array}$ & ED/HA & $\begin{array}{l}\text { - MRI with } \\
\text { DWI (all } \\
\text { patients) }\end{array}$ & High/NA & $\begin{array}{l}\text { Prospective case } \\
\text { series } \\
\text { (consecutive) }\end{array}$ & $\begin{array}{l}\text { Retrospective analysis of data } \\
\text { from a prospective stroke } \\
\text { registry. }\end{array}$ \\
\hline Lee et al. ${ }^{10}$ & $25 \quad(25)$ & $\begin{array}{l}\text { AVS and diagnosis of } \\
\text { cerebellar infarction } \\
\text { (clinical findings and } \\
\text { audiovestibular testing, } \\
\text { vascular territory) }\end{array}$ & $\mathrm{ED} / \mathrm{HA}$ & $\begin{array}{l}\text { - MRI with } \\
\text { DWI, and MRA } \\
\text { (all patients) }\end{array}$ & High/NA & $\begin{array}{l}\text { Prospective case } \\
\text { series } \\
\text { (consecutive) }\end{array}$ & $\begin{array}{l}\text { Patients with brainstem/ } \\
\text { cerebellar dysfunction other than } \\
\text { nystagmus were excluded. } \\
\text { Retrospective analysis of data } \\
\text { from a prospective stroke } \\
\text { registry. }\end{array}$ \\
\hline Cnyrim et al. ${ }^{11}$ & NR (83) & $\begin{array}{l}\text { AVS and diagnosis of } \\
\text { vestibular neuritis or } \\
\text { pseudoneuritis } \\
\text { (diagnosis, clinical } \\
\text { features) }\end{array}$ & ED & $\begin{array}{l}\text { - MRI with } \\
\text { DWI (all } \\
\text { patients) }\end{array}$ & High/Medium & $\begin{array}{l}\text { Case-control } \\
\text { study (possibly } \\
\text { prospective, } \\
\text { possibly } \\
\text { consecutive) }\end{array}$ & $\begin{array}{l}\text { Initial MRI obtained within } 5 \mathrm{~d} \\
\text { of symptom onset; no further } \\
\text { breakdown provided. No follow- } \\
\text { up MRI or clinical follow-up in } \\
\text { patients with initially negative } \\
\text { MRI. Patients with hearing loss or } \\
\text { brainstem/cerebellar dysfunction } \\
\text { other than nystagmus were } \\
\text { excluded. Retrospective data } \\
\text { analysis. Selection of controls not } \\
\text { described. }\end{array}$ \\
\hline Moon et al. ${ }^{33}$ & $7 \quad(7)$ & $\begin{array}{l}\text { Acute vertigo and } \\
\text { diagnosis of isolated } \\
\text { infarction of the cerebellar } \\
\text { nodulus (clinical features, } \\
\text { audiovestibular findings) }\end{array}$ & ED/HA & $\begin{array}{l}\text { - MRI with } \\
\text { DWI, and MRA } \\
\text { (all patients) }\end{array}$ & $\mathrm{High} / \mathrm{NA}$ & $\begin{array}{l}\text { Retrospective } \\
\text { case series }\end{array}$ & $\begin{array}{l}\text { One of } 8 \text { patients reported had a } \\
\text { transient positional vertigo } \\
\text { syndrome rather than AVS. }\end{array}$ \\
\hline $\begin{array}{l}\text { Kattah et al. }{ }^{6} \\
\text { (preliminary } \\
\text { report in } \\
\text { Newman-Toker } \\
\text { et al. } .^{12} \text { ) }\end{array}$ & $121(101)$ & $\begin{array}{l}\text { AVS and } \geq 1 \text { risk factor } \\
\text { for stroke (diagnosis, } \\
\text { clinical features, } \\
\text { imaging) }\end{array}$ & ED/HA & $\begin{array}{l}\text { - MRI with } \\
\text { DWI (all } \\
\text { patients) }\end{array}$ & High/High & $\begin{array}{l}\text { Prospective } \\
\text { cross-sectional } \\
\text { study } \\
\text { (consecutive } \\
\text { cases) }\end{array}$ & $\begin{array}{l}\text { Patients with initially negative } \\
\text { MRI underwent repeat MRI } \\
\text { owing to unexplained signs } \\
\text { suggesting central location. }\end{array}$ \\
\hline $\begin{array}{l}\text { Lee et al. }{ }^{27} \dagger \\
\text { (preliminary } \\
\text { report in Lee } \\
\text { et al al. }{ }^{34} \text { and Lee } \\
\text { and }\left(\mathrm{Cho}^{35} \text { ) }\right.\end{array}$ & $80 \quad(80)$ & $\begin{array}{l}\text { AVS and AICA stroke } \\
\text { (audio-vestibular } \\
\text { findings, topography of } \\
\text { lesion) }\end{array}$ & $\mathrm{ED} / \mathrm{HA}$ & $\begin{array}{l}\text { - MRI with } \\
\text { DWI, and MRA } \\
\text { (all patients) }\end{array}$ & $\mathrm{High} / \mathrm{NA}$ & $\begin{array}{l}\text { Prospective case } \\
\text { series } \\
\text { (consecutive) }\end{array}$ & $\begin{array}{l}\text { Retrospective analysis of data } \\
\text { from prospective stroke registry. } \\
\text { Most MRIs obtained within } 30 \mathrm{~d} \\
\text { after symptom onset. }\end{array}$ \\
\hline \multicolumn{8}{|c|}{ 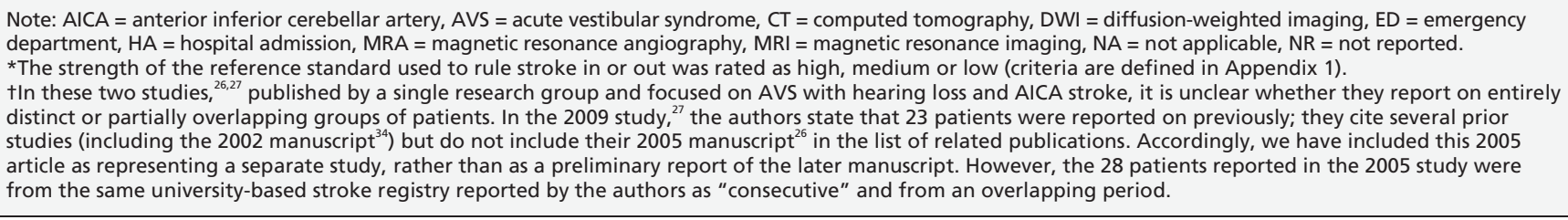 } \\
\hline
\end{tabular}


syndrome. Table 3 lists attributes of the chief symptom, associated symptoms and risk factors, including their strength as predictors of central versus peripheral causes.

\section{Chief symptom of dizziness}

Although not evidence-based, classic teaching ${ }^{72}$ and current practice ${ }^{20}$ in the United States divides dizziness into four types based on symptom quality, each said to predict the underlying cause: vertigo (false sense of spinning or motion), presyncope, unsteadiness, and nonspecific or other type of dizziness. ${ }^{73,74}$ This approach differs slightly from European practice ${ }^{37}$ and from terminology for a planned international classification of vestibular disorders ${ }^{75}$ which define dizziness and vertigo separately. In keeping with current North American practice, ${ }^{20}$ for this review we use dizziness as an umbrella term that includes vertigo as a subset, recognizing, however, that recent data suggest drawing any linguistic distinction between dizziness and vertigo probably has little diagnostic value.

\section{Type}

The type of dizziness is typically the main focus for directing diagnostic inquiry, ${ }^{76}$ as described in numerous textbooks and review articles ${ }^{24}$ and reported in a multicentre clinical practice survey of more than 400 emergency physicians. ${ }^{20}$

None of the studies included in our systematic review examined type of dizziness as a predictor of the causes in acute vestibular syndrome. A critical review of the literature suggested that this approach is not an evidencebased practice. ${ }^{24} \mathrm{~A}$ study involving more than
300 consecutive patients presenting to an emergency department with acute dizziness showed type of dizziness to be an imprecise metric. More than half of the patients were unable to reliably report which symptom type most accurately reflected their experience. ${ }^{37}$

More importantly, the type of dizziness does not appear to be a trustworthy predictor of the underlying cause. In a population-based study involving patients presenting to emergency departments with dizziness that was not focused specifically on acute vestibular syndrome, patients with unsteadiness as part of their symptom complex were at a slightly increased risk of stroke, but the presence of vertigo versus other types of dizziness was found to predict stroke with equal likelihood. ${ }^{15}$

These results support those of disease-based studies (reviewed elsewhere ${ }^{37}$ ) that indicated that type of dizziness was inconsistently described by patients with disorders known to cause acute vestibular syndrome such as vestibular neuritis, ${ }^{77}$ stroke in the posterior fossa ${ }^{47,52}$ and cerebellar hemorrhage. ${ }^{78}$

\section{Duration}

To meet the clinical definition of acute vestibular syndrome, the patient must have continuous dizziness for more than 24 hours. This excludes most disorders in which dizziness typically presents with transient episodes lasting seconds, minutes or hours, such as benign paroxysmal positional vertigo, Menière disease, vestibular migraine, cardiac arrhythmia and transient ischemic attack. These disorders rarely remain diagnostic considerations beyond the first few

Table 2: Central causes of acute vestibular syndrome in three relevant studies from the systematic review*

\begin{tabular}{|c|c|c|c|c|}
\hline Central cause & $\begin{array}{c}\text { Norrving et al. }{ }^{9} \\
n=7\end{array}$ & $\begin{array}{c}\text { Cnyrim et al. }{ }^{11} \\
n=43\end{array}$ & $\begin{array}{c}\text { Kattah et al. }{ }^{6} \\
n=76 \dagger\end{array}$ & $\begin{array}{c}\text { Total no. (\%) } \\
\text { of patients } \\
n=126\end{array}$ \\
\hline Cerebrovascular event in posterior fossa & $7 \S$ & 24 & 73 [37] & $104(83)$ \\
\hline Ischemic stroke (cerebellum or brainstem) & 7 & 23 & $69[36]$ & 99 (79) \\
\hline Hemorrhage (cerebellum or brainstem) & 0 & 1 & $4[1]$ & $5 \quad(4)$ \\
\hline Other central/equivocal cause & 0 & 7 & $1[0]$ & $8 \quad(6)$ \\
\hline \multicolumn{5}{|c|}{ 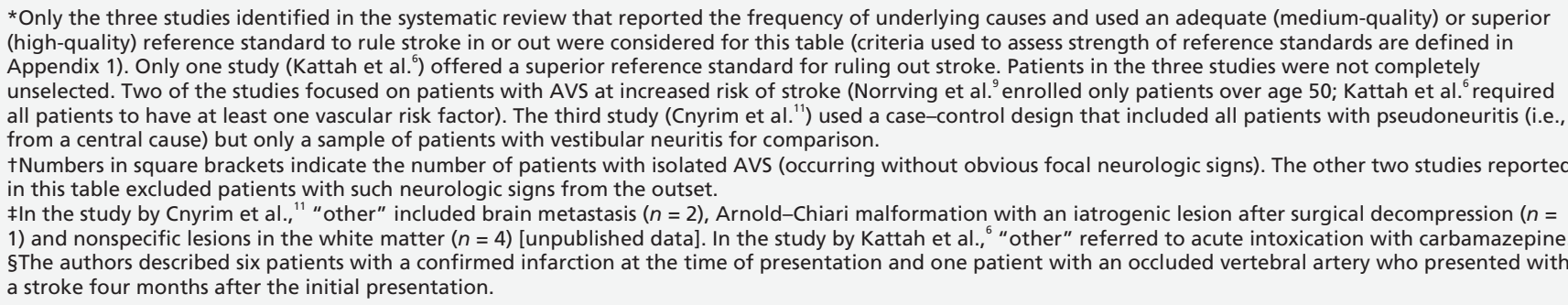 } \\
\hline
\end{tabular}


hours in patients with acute vestibular syndrome. Vestibular migraine may be an exception: in two large case series, up to $27 \%$ of patients with that condition reported dizziness that persisted for more than 24 hours. ${ }^{53,54}$

\section{Onset}

Some experts suggest that abrupt onset of dizziness in acute vestibular syndrome favours a vascular cause, whereas a more gradual onset, over hours, indicates vestibular neuritis. ${ }^{5}$ Although none of the studies included in our systematic review compared the timing of onset across disorders, two uncontrolled, retrospective case series identified in our critical review reported that dizziness was typically abrupt in onset among patients with a cerebrovascular cause of acute dizziness. ${ }^{48,49}$

\section{Prodromal dizziness}

None of the studies in our systematic review reported on prodromal dizziness. A critical review of other evidence on transient, isolated episodes of prodromal dizziness preceding a presentation of acute vestibular syndrome suggested a prevalence of about $25 \%$ among patients with vestibular neuritis $^{50,51}$ and a similar prevalence among patients with vertebrobasilar stroke. ${ }^{26,48,49}$ As a harbinger of stroke, these episodes presumably represent transient ischemic attacks.

A single episode of transient dizziness within a few days before a presentation of acute vestibular syndrome is probably nonspecific (reported with high frequency among patients with vestibular neuritis and those with stroke). However, recurrent episodes lasting seconds to minutes over the preceding weeks or months may favour a cerebrovascular cause. Recurrent episodes were reported in two retrospective case series of patients with cerebrovascular dizziness. ${ }^{48,49}$ In the larger series, 29\% (12/42) of patients with vertebrobasilar stroke had prodromal, isolated episodes of dizziness for up to two years before the stroke. ${ }^{49}$

Box 1: Differential diagnosis of acute vestibular syndrome based on expert opinion

\section{Less urgent causes}

Common

- Vestibular neuritis or labyrinthitis

- Multiple sclerosis

Uncommon $(<1 \%)$ or unknown frequency

- CNS adverse effects (e.g., antiepileptics)

- Medication ototoxicity (e.g., postaminoglycoside)

- Other CNS inflammation (e.g., sarcoidosis)

- Prolonged attack of episodic ataxia syndrome

- Prolonged attack of Menière disease

- Prolonged attack of vestibular migraine

- Traumatic vestibulopathy (including surgical)

Presumed possible*

- Atypical infection (otosyphilis, Lyme disease)

- Celiac disease

- Cerebello-pontine angle neoplasm

- Degenerative cerebellar ataxia

- Drug intoxication (e.g., alcohol, illicit drugs)

\section{More urgent causes}

Common

- Brainstem or cerebellar infarction

- Brainstem or cerebellar hemorrhage

Uncommon $(<1 \%)$ or unknown frequency

- Bacterial labyrinthitis/mastoiditis

- Brainstem encephalitis (e.g., listeria, paraneoplastic)

- Brainstem hypertensive encephalopathy

- Herpes zoster oticus (Ramsay Hunt syndrome)†

- Labyrinthine strokeł

- Wernicke syndrome (vitamin $B_{1}$ deficiency)

- Miller Fisher syndrome

Presumed possible*

- Altitude sickness or hypoxia

- Basilar meningitis (e.g., tuberculosis)

- Cerebral infarction or hemorrhage§

- CNS medication toxicity (e.g., lithium)

- Decompression sickness

- Electrolyte imbalance (e.g., hyponatremia)

- Endocrine disorders (e.g., acute adrenal insufficiency)

- Environmental toxins (e.g., carbon monoxide)

- Subarachnoid hemorrhage/aneurysm

Note: $\mathrm{CNS}=$ central nervous system

*These conditions are known to cause acute dizziness, but whether they can present with a clinically complete or clinically predominant picture of acute vestibular syndrome remains unknown.

tRisk of permanent hearing loss or facial palsy without treatment.

¥The frequency of infarction of the labyrinthine artery is difficult to estimate given that the current reference standard test for confirming the diagnosis (autopsy with temporal bone histology) is rarely performed. Recent studies, however, suggest that patients with sudden deafness, with or without dizziness, are at increased risk of stroke, which suggests a possible vascular mechanism. ${ }^{27,4}$

§Acute vestibular syndrome secondary to cerebrovascular disease is strongly associated with posterior fossa infarcts. ${ }^{6}$

Transient dizziness may be present in up to $10 \%$ of patients with right-hemispheric stroke, ${ }^{42}$ and patients with isolated insular or parietal infarction may present with dizziness (including true vertigo) as the chief symptom. ${ }^{43,44} \mathrm{However}$, the precise duration of symptoms and the extent to which the clinical pattern may match that of acute vestibular syndrome remains unknown. 
Most strokes after transient ischemic attacks occur within the first 90 days after the index event. ${ }^{79}$ The increased risk of stroke after discharge from an emergency department with a (mis)diagnosis of benign dizziness declines rapidly within 60 days and returns to baseline by six months. ${ }^{19}$ Therefore, recurrent events over a more protracted period could suggest a lowerrisk pathogenic mechanism such as episodic hemodynamic insufficiency in a patient with a slowly progressive vasculopathy.

\section{Triggers}

In patients with transient dizziness, there is little controversy that the triggers of the dizziness represent a key source of diagnostic information (e.g., for those with benign paroxysmal positional vertigo or orthostatic hypotension, which are triggered by positional changes ${ }^{7}$ ). A clinical practice survey of emergency physicians ${ }^{20}$ and a controlled study comparing knowledge of generalists and specialists ${ }^{55}$ suggested that overgeneralization of this rule to include acute vestibular syndrome leads to the common misconception that exacerbation of symptoms with head movement (as with the Dix-Hallpike positional test for benign paroxysmal positional vertigo) predicts a peripheral cause.

Although our systematic review identified no data on triggers as a predictor of the underlying cause of acute vestibular syndrome, experts agree that patients with acute vestibular syndrome tend to be intolerant of head motion during the acute stage, regardless of the underlying cause of the dizziness. ${ }^{55}$ In keeping with expert opinion, exacerbation of symptoms or signs with head motion or positional testing has been reported in both vestibular neuritis ${ }^{51}$ and stroke. ${ }^{80}$

\section{Associated symptoms and risk factors}

Patients with dizziness can present with other symptoms or signs that may be used to distinguish between peripheral and central causes of acute vestibular syndrome. The presence or absence of specific risk factors may also be used in determining the diagnosis.

\section{Neurologic symptoms or signs}

Narrative reviews have generally suggested that the presence of neurologic symptoms or signs indicates a central cause of acute vestibular syndrome, and some authors have gone so far as to suggest that their absence indicates a peripheral cause. . $^{81,82}$

Most of the studies in our systematic review considered only patients with isolated acute vestibular syndrome, excluding those with major neurologic symptoms beyond the core features of acute vestibular syndrome (dizziness, nausea or vomiting, and gait disturbance). In studies that included patients with general neurologic symptoms or signs (e.g., diplopia and numbness), the presence of such symptoms or signs was strongly associated with central causes, but their absence was a relatively poor predictor of a peripheral cause. ${ }^{6,27,31}$

\section{Proportionality of symptoms}

Proportionality of dizziness, autonomic symptoms, and gait or postural symptoms has sometimes been cited by experts as typical of peripheral vestibular disorders, whereas central disorders are said to be occasionally associated with disproportionate symptoms (e.g., severe gait impairment with a mild subjective sense of dizziness). ${ }^{22,24}$ Our critical review identified some weak evidence to support this contention. Authors of uncontrolled case reports and small case series hypothesized that the presence of vomiting $^{52,83,84}$ or imbalance and gait unsteadiness ${ }^{52}$ that was out of proportion to the degree of dizziness or nystagmus may be a marker of brainstem or cerebellar pathology, including stroke.

The largest case series we found that addressed these associations (66 patients with cerebellar stroke) noted disproportionate vomiting or gait unsteadiness to be particularly common among patients with infarcts of the superior cerebellar artery $(n=30) .{ }^{52}$ Of the $40 \%(12 / 30)$ who had vomiting at stroke onset, only $42 \%(5 / 12)$ had dizziness. In the same study, 67\% (20/30) were unable to walk or stand unaided, but only $37 \%(11 / 30)$ of these patients had dizziness. ${ }^{52}$ The study did not indicate, however, whether all patients presented with acute vestibular syndrome.

\section{Auditory symptoms}

Expert opinion grounded in well-established neuroanatomy suggests that auditory symptoms usually point to a peripheral cause in patients with dizziness (see review by Newman-Toker ${ }^{24}$ ). Unfortunately, when translated into a bedside prediction rule, this anatomic fact may lead to the mistaken diagnosis of a more benign cause. ${ }^{68}$

The vascular supply to the inner ear derives from the posterior cerebral circulation, and combined audiovestibular presentations are known to occur in patients with cerebrovascular disease..$^{23}$ Patients with auditory symptoms have generally been excluded from major studies of acute vestibular syndrome and vestibular neuritis. ${ }^{68}$ None of the studies included in our systematic review adequately assessed auditory symptoms as a specific predictor of peripheral versus central causes.

Nevertheless, recent evidence suggests that auditory symptoms in patients presenting with 
Table 3: Clinical findings as predictors of stroke versus vestibular neuritis in patients presenting with acute vestibular syndrome (AVS) (part 1 of 2)

\begin{tabular}{|c|c|c|c|c|c|}
\hline Clinical finding & Predicts & $\begin{array}{l}\text { Strength of } \\
\text { predictor }\end{array}$ & $\begin{array}{l}\text { Type of } \\
\text { review }\end{array}$ & $\begin{array}{l}\text { Level of } \\
\text { evidence* }\end{array}$ & Comments \\
\hline \multicolumn{6}{|l|}{ Chief symptom } \\
\hline $\begin{array}{l}\text { Dizziness of gradual } \\
\text { onset }\end{array}$ & Neuritis & $\begin{array}{l}\text { Probably } \\
\text { strong }\end{array}$ & Critical & 4 & $\begin{array}{l}\text { Onset of dizziness is gradual (hours to days) in few } \\
\text { patients with stroke; }{ }^{48,49} \text { little is known about } \\
\text { characteristics of onset in neuritis, but some experts } \\
\text { suggest that gradual onset over hours is typical }\end{array}$ \\
\hline $\begin{array}{l}\text { Dizziness of abrupt } \\
\text { onset }\end{array}$ & Stroke & Uncertain & Critical & 4 & $\begin{array}{l}\text { Onset of dizziness is abrupt (seconds to minutes) in a } \\
\text { large proportion of patients with stroke }{ }^{49} \text { little is known } \\
\text { about characteristics of onset in neuritis, but some } \\
\text { patients wake up with symptoms }\end{array}$ \\
\hline $\begin{array}{l}\text { Multiple prodromal } \\
\text { episodes of dizziness }\end{array}$ & Stroke & Strong & Critical & $3 b$ & $\begin{array}{l}\text { Multiple episodes in the } 6 \text { months before onset of AVS, } \\
\text { particularly in the weeks before AVS, have been reported } \\
\text { only as TIAs preceding stroke }{ }^{48,49}\end{array}$ \\
\hline $\begin{array}{l}\text { Single prodromal } \\
\text { episode of dizziness }\end{array}$ & No & - & Critical & $3 b$ & $\begin{array}{l}\text { A single episode in the } 48 \text { hours before onset of AVS is } \\
\text { reported in } 1 \text { in } 4 \text { patients, regardless of the cause } \\
\text { (vestibular neuritis v. stroke) } \text { ) }^{26,48-51}\end{array}$ \\
\hline $\begin{array}{l}\text { Type of dizziness } \\
\text { (vertigo v. other) }\end{array}$ & No & - & Critical & $2 b$ & $\begin{array}{l}\text { Type of dizziness is imprecisely reported by patients; }{ }^{37} \\
\text { disease-based studies indicate substantial overlap in type } \\
\text { reported for different diseases, }{ }^{24,37} \text { including stroke in the } \\
\text { posterior fossa }{ }^{15,52}\end{array}$ \\
\hline $\begin{array}{l}\text { Total duration of } \\
\text { dizziness }>24 \mathrm{~h}\end{array}$ & No & - & Critical & 4 & $\begin{array}{l}\text { Duration of dizziness varies by cause; continuous } \\
\text { duration }>24 \mathrm{~h} \text { for new, acute symptoms eliminates } \\
\text { most transient causes (e.g., benign paroxysmal positional } \\
\text { vertigo) except migraine, } \\
\text { among causes of AVS }\end{array}$ \\
\hline Triggers of dizziness & No & - & Critical & 5 & $\begin{array}{l}\text { Triggers predict cause in patients with brief episodes, but } \\
\text { provocative factors (e.g., symptoms worsen with head } \\
\text { motion) do not distinguish central from peripheral } \\
\text { causes of } \mathrm{AVS}^{20,55}\end{array}$ \\
\hline \multicolumn{6}{|l|}{ Associated symptoms } \\
\hline $\begin{array}{l}\text { Painless (no neck pain or } \\
\text { headache) }\end{array}$ & Neuritis & $\begin{array}{c}\text { Weak } \\
(\text { NLR } 0.70)^{6}\end{array}$ & Both & $2 a$ & $\begin{array}{l}\text { Head or neck pain is present in a minority of patients } \\
\text { with AVS whether due to stroke or neuritis; frequency } \\
\text { lower in peripheral AVS; pain is absent in } 1 \text { of } 4 \\
\text { dissections of vertebral artery }\end{array}$ \\
\hline $\begin{array}{l}\text { Craniocervical pain (e.g., } \\
\text { headache, neck pain) }\end{array}$ & Stroke & $\begin{array}{l}\text { Moderate } \\
(\text { PLR 3.2) }\end{array}$ & Both & $2 a$ & $\begin{array}{l}\text { Craniocervical pain is reported frequently in cerebellar } \\
\text { infarctions and dissections of vertebral artery; }{ }^{6,9,22} \\
\text { frequency is lower in peripheral AVS; pain that is } \\
\text { characterized as sudden, }{ }^{57-60} \text { severe } e^{58,61,62} \text { or sustained }(>72 \\
\text { h) }{ }^{60} \text { may indicate increased likelihood of stroke }\end{array}$ \\
\hline $\begin{array}{l}\text { Neurologic symptom } \\
\text { including diplopia }\end{array}$ & Stroke & $\begin{array}{l}\text { Probably } \\
\text { strong }\end{array}$ & Critical & 4 & $\begin{array}{l}\text { Double vision, slurred speech, trouble swallowing, } \\
\text { hoarseness and other "posterior circulation" symptoms } \\
\text { suggest stroke, although rare exceptions probably do occur }{ }^{63}\end{array}$ \\
\hline $\begin{array}{l}\text { Disproportionate } \\
\text { symptomt (gait or } \\
\text { nausea) }\end{array}$ & Stroke & Unknown & Critical & 4 & $\begin{array}{l}\text { Symptoms of gait/postural imbalance or nausea/vomiting } \\
\text { in excess of symptomatic experience of dizziness is } \\
\text { described with central causes }\end{array}$ \\
\hline $\begin{array}{l}\text { Auditory symptoms } \\
\text { (e.g., hearing loss) }\end{array}$ & Stroke (?) & Unknown & Both & 4 & $\begin{array}{l}\text { Several case series have reported auditory symptoms } \\
\text { (particularly hearing loss) as a frequent symptom in AICA } \\
\text { infarctions; }{ }^{23,27} \text { relative frequency of benign causes } \\
\text { (labyrinthitis) unknown }\end{array}$ \\
\hline \multicolumn{6}{|l|}{ Risk factors } \\
\hline Age $<50 \mathrm{yr}$ & Neuritis & $\begin{array}{l}\text { Probably } \\
\text { weak }\end{array}$ & Both & $3 b$ & $\begin{array}{l}25 \% \text { of patients with AVS due to stroke are }<50 \mathrm{yr}^{\text {old }}{ }^{6} \\
\text { younger patients with AVS often have dissection of } \\
\text { vertebral artery as a cause; } \text { stroke misdiagnosis is more }^{6} \text { common in patients }<50 \mathrm{yr}^{16,64}\end{array}$ \\
\hline Age $>50 \mathrm{yr}$ & Stroke & Strong & Both & $3 b$ & $\begin{array}{l}\text { Age is a known risk factor for stroke and has been used } \\
\text { to "enrich" AVS research populations with stroke; }{ }^{9} \\
\text { nevertheless, isolated AVS in patients aged }>50 \mathrm{yr} \text { is } \\
\text { probably still more often neuritis }\end{array}$ \\
\hline $\begin{array}{l}\text { Other vascular risk } \\
\text { factors§ }\end{array}$ & Stroke & Moderate & Both & $3 b$ & $\begin{array}{l}\text { Patients with } \geq 1 \text { vascular risk factor appear to be at } \\
\text { increased risk of stroke }{ }^{6} \text { (among those with isolated AVS, } \\
\text { estimated prevalence about } 30 \%-50 \% \text { v. about } 10 \%- \\
20 \% \text { among those without risk factors) }\end{array}$ \\
\hline
\end{tabular}


Table 3: Clinical findings as predictors of stroke versus vestibular neuritis in patients presenting with acute vestibular syndrome (AVS) (part 2 of 2)

\begin{tabular}{|c|c|c|c|c|c|}
\hline Clinical finding & Predicts & $\begin{array}{l}\text { Strength of } \\
\text { predictor }\end{array}$ & $\begin{array}{l}\text { Type of } \\
\text { review }\end{array}$ & $\begin{array}{l}\text { Level of } \\
\text { evidence* }\end{array}$ & Comments \\
\hline History of trauma & Stroke & Moderate & Critical & 4 & $\begin{array}{l}\text { Recent head or neck trauma is a risk factor for dissection } \\
\text { of the vertebral artery (PLR } 3.8))^{65} \text { in AVS, trauma (even } \\
\text { minor) should spark concern for dissection, even if pain is } \\
\text { absent }\end{array}$ \\
\hline No trauma & No & - & Critical & 4 & $\begin{array}{l}>50 \% \text { of symptomatic dissections of the vertebral artery } \\
\text { occur without an identifiable history of trauma, most } \\
\text { often in patients without known collagen-vascular } \\
\text { disorders }{ }^{56,65}\end{array}$ \\
\hline $\begin{array}{l}\text { Comorbid illness or } \\
\text { surgery }\end{array}$ & Variable & - & Critical & 5 & $\begin{array}{l}\text { Patients with a history of malnutrition (Wernicke syndrome), } \\
\text { a compromised immune system (encephalitis, herpes zoster } \\
\text { oticus), ear surgery (mastoiditis) or drug exposure } \\
\text { (aminoglycoside ototoxicity) are presumably more likely to } \\
\text { have a cause linked to their illness or exposure }\end{array}$ \\
\hline \multicolumn{6}{|l|}{ Physical examination } \\
\hline $\begin{array}{l}\text { General neurologic signs } \\
\text { absent }\end{array}$ & Neuritis & $\begin{array}{c}\text { Weak } \\
(\text { NLR } 0.81)^{6}\end{array}$ & Systematic & $2 a$ & $\begin{array}{l}\text { Not counting oculomotor findings or severe gait or } \\
\text { truncal ataxia, absence of neurologic signs excludes only } \\
\text { about } 1 \text { of } 5 \text { strokes causing AVS }{ }^{6}\end{array}$ \\
\hline $\begin{array}{l}\text { All neurologic signs } \\
\text { absent }\end{array}$ & Neuritis & $\begin{array}{l}\text { Moderate } \\
(\text { NLR } 0.36)^{6}\end{array}$ & Systematic & $2 a$ & $\begin{array}{l}\text { Not counting findings from HINTS battery of tests, } \\
\text { absence of all neurologic symptoms or signs, including } \\
\text { severe gait or truncal ataxia, excludes about } 2 \text { of } 3 \\
\text { strokes causing } \text { AVS }^{6}\end{array}$ \\
\hline $\begin{array}{l}\text { No dangerous signs } \\
\text { (INFARCT) on HINTS } \\
\text { battery of tests }\end{array}$ & Neuritis & $\begin{array}{l}\text { Very strong } \\
\text { (NLR 0.02) }\end{array}$ & $\begin{array}{l}\text { Systematic } \\
\text { (see text) }\end{array}$ & $\begin{array}{c}1 \mathrm{~b} \\
{[\mathrm{GRADE}} \\
\left.\text { strong }(\uparrow \uparrow)^{* *}\right]\end{array}$ & $\begin{array}{l}\text { The benign triad of abnormal result of unilateral head } \\
\text { impulse test (away from nystagmus fast phase), } \\
\text { direction-fixed dominantly horizontal nystagmus, and } \\
\text { absent vertical ocular misalignment (skew) virtually } \\
\text { excludes stroke in patients who have AVS without } \\
\text { auditory symptoms, }\end{array}$ \\
\hline $\begin{array}{l}\text { Normal result of head } \\
\text { impulse test }\end{array}$ & Stroke & $\begin{array}{l}\text { Strong } \\
\text { (PLR 18) }\end{array}$ & $\begin{array}{l}\text { Systematic } \\
\text { (see } \\
\text { Table 4) }\end{array}$ & $\begin{array}{c}1 a \\
{[G R A D E} \\
\left.\text { strong }(\uparrow \uparrow)^{* *}\right]\end{array}$ & $\begin{array}{l}\text { In a patient with AVS, a normal result of the horizontal } \\
\text { head impulse test in both directions is a strong predictor } \\
\text { of stroke as a cause, even if all other findings suggest } \\
\text { neuritis, }\end{array}$ \\
\hline $\begin{array}{l}\text { Any neurologic signs } \\
\text { present }\end{array}$ & Stroke & $\begin{array}{l}\text { Probably } \\
\text { very strong }\end{array}$ & Systematic & $2 a$ & $\begin{array}{l}\text { Any new neurologic signs, including severe gait or } \\
\text { truncal ataxia, are probably strong predictors of a central } \\
\text { cause, usually stroke, and generally exclude neuritis }{ }^{63}\end{array}$ \\
\hline $\begin{array}{l}\text { Other vestibular- } \\
\text { oculomotor signs }\end{array}$ & Unknown & - & Both & $4 / 5$ & $\begin{array}{l}\text { Characteristics of spontaneous nystagmus (vector, } \\
\text { fixation suppression, pattern, appearance with } \\
\text { provocation) and abnormal visual smooth pursuit are } \\
\text { understudied }\end{array}$ \\
\hline
\end{tabular}

Note: AICA = anterior inferior cerebellar artery, AVS = acute vestibular syndrome, HINTS = head impulse, nystagmus, test of skew, INFARCT = impulse normal, fastphase alternating, refixation on cover test, NLR = negative likelihood ratio, PLR = positive likelihood ratio, TIA $=$ transient ischemic attack.

*Level of evidence was defined by a single rater (D.N.T.) according to the Oxford Centre for Evidence-based Medicine. ${ }^{66}$ The highest level of evidence is " $1 a^{\prime \prime}$ (based on systematic review of level 1 studies with homogeneity) and the lowest level of evidence is " 5 " (expert opinion without explicit critical appraisal or based on physiology or "first principles"). Evidence failing to meet strict inclusion criteria for the systematic review was considered part of the critical review; studies that achieved a higher evidence rating yet were not included in the systematic review were generally studies in which the AVS population was incompletely defined (e.g., AVS patients included along with patients who had non-AVS dizziness, with predictors not defined separately for the two groups). In addition, a GRADE strength recommendation (www.gradeworkinggroup.org/) for adoption of evidence related to the clinical predictors is provided for exam elements that achieved a level 1 rating (see footnote below for details).

tRefers to proportionality of vestibular (dizziness), autonomic (nausea or vomiting), and gait or postural symptoms. Disproportionate symptoms would be, for example, severe gait impairment with a mild subjective sense of dizziness.

‡Auditory symptoms have not been adequately studied as a specific predictor of central versus peripheral causes of AVS. The vascular supply to the inner ear derives from the posterior cerebral circulation, and combined audiovestibular presentations appear to be common among patients with cerebrovascular disease. ${ }^{23}$ Some uncommon, nonvascular peripheral vestibular disorders, such as herpes zoster oticus (Ramsay Hunt syndrome) are also known to produce combined audiovestibular presentations (i.e., AVS with hearing loss or tinnitus) that can be abrupt in onset. ${ }^{67}$ Patients with auditory symptoms have generally been excluded from major studies of AVS or vestibular neuritis. ${ }^{68}$ This includes even the highest quality study identified in our systematic review, which excluded patients with a prior history of auditory symptoms (although not those with new, acute symptoms, which were identified in 2 of 69 patients with stroke and 0 of 25 with neuritis). ${ }^{6}$ Future studies of AVS should prospectively enrol patients with and those without auditory symptoms.

§Includes smoking, hypertension, diabetes, hyperlipidemia, atrial fibrillation, eclampsia, hypercoagulable state, recent cervical trauma and prior stroke or myocardial infarction. ${ }^{6}$

**The GRADE level of evidence for recommending the use of the HINTS approach to diagnose AVS or the use of normal result of head impulse test alone as a stroke predictor is level B (moderate). This quality assessment is based on homogeneous and consistent results from multiple research groups for individual oculomotor findings (including the normal result of head impulse test) and one high-quality cross-sectional study in an appropriate, unbiased population with diagnostic uncertainty and direct comparison of results of HINTS battery of tests with an appropriate reference standard. ${ }^{69}$ The level of evidence is downgraded from "high quality" for indirectness (study of diagnostic accuracy without health outcomes measurement [-1], sparse specificity data [-1] and uncertain generalizability beyond subspecialists $[-1])$; these effects are mitigated by a very strong association/effect size $(+2) .{ }^{69,70}$ Considering the balance of benefits, risks and alternatives for stroke diagnosis (i.e., routine use of insensitive CT or more expensive, less readily available, and less sensitive MRI), the GRADE recommendation for adequately trained providers to use the HINTS approach to stroke diagnosis (or a normal result of head impulse test to predict stroke) in patients with AVS is "strong $(\uparrow \uparrow) .{ }^{\prime 71}$ 
acute vestibular syndrome can and do result from ischemic disturbance of the inner ear, often in association with frank infarction of the posterior circulation in the territory supplied by the anterior inferior cerebellar artery..$^{22,27}$ In our systematic review, we identified three studies from one research group reporting on transient dizziness and hearing loss, with or without tinnitus, as a premonitory transient ischemic attack that can precede audiovestibular loss due to infarction of the anterior inferior cerebellar artery in up to $42 \%$ of patients. ${ }^{26,27,34}$

Our critical review identified a recent study in which patients admitted to hospital with sudden hearing loss were found to be at increased risk of stroke (odds ratio [OR] 1.64, 95\% CI 1.31-2.07) relative to patients undergoing appendectomy (control group in general hospital population) during the five-year period following hospital admission. ${ }^{41}$ Although not sought out as part of that study's design, dizziness or vestibular symptoms presumably occurred concurrently with the hearing loss in some patients.

\section{Craniocervical pain}

Narrative reviews have suggested that craniocervical pain may accompany dizziness in patients with stroke in the posterior fossa because of the stroke itself (mass effect or direct involvement of pain-sensitive structures) or its underlying cause (e.g., dissection or aneurysm of the vertebral artery). ${ }^{22}$ Two studies included in our systematic review addressed this issue. Headache or neck pain was present in a minority of patients presenting with acute vestibular syndrome $\left(38 \%, n=9 / 24 ;^{9}\right.$ and $29 \%, n=$ $\left.29 / 101^{6}\right)$. A statistically significant association with central causes $(38 \%$ v. $12 \%, p<0.05)$ was found in the larger study.

A narrative review of related literature indicated that vestibular migraine is a diagnostic consideration in almost any patient with dizziness and headache. ${ }^{85}$ None of the studies in our systematic review identified migraine as a cause of acute vestibular syndrome in their patient population. However, in our critical review, we found that young patients with dissection of the vertebral artery and stroke in the posterior fossa may be at particularly high risk of receiving a misdiagnosis of migraine. ${ }^{16}$

A recent systematic review indicated that dizziness, headache and neck pain are the three most common symptoms of dissection of the vertebral artery. ${ }^{56}$ Nevertheless, the absence of head or neck pain appeared to be diagnostically inconclusive with regard to ruling out dissection: about one in four patients with dissection presented without head or neck pain. ${ }^{56}$ The gradual onset of pain over hours and the disappearance of pain within $24-48$ hours typify migraine,${ }^{86}$ and the headaches of vestibular migraine are often relatively mild. ${ }^{54}$ By contrast, data from case series suggest that craniocervical pain in patients with dissection of the vertebral artery is often sudden, severe or sustained. Among patients with confirmed dissection, pain was sudden in $57 \%(n=43 / 75)^{57-60}$ and severe in $60 \%(n=$ 41/68)..$^{58,61,62}$ Headache was sustained (i.e., > 72 hours) in $100 \%(n=12 / 12)$ in one series ${ }^{60}$ and lasted 2-35 days (mean 8.3 days, median 3 days) in another series $(n=18) .^{59}$ Whether these proportions were enriched by diagnostic ascertainment bias is unknown.

\section{Concurrent illnesses and exposures}

When obtaining the medical history from a patient with acute vestibular syndrome, one should identify any major known concurrent illnesses (e.g., multiple sclerosis, HIV/AIDS, metastatic cancer, severe malnutrition and major depression) or potentially relevant exposures (e.g., viral syndrome, ear surgery, bacterial otitis media and ototoxic medications [especially aminoglycoside antibiotics or chemotherapy agents]) in addition to assessing vascular risk factors. Our systematic search identified no evidence on the predictive value of any of these variables, although common sense dictates that certain ones (e.g., recent surgery involving the middle ear) are more likely to be predictive than others (e.g., recent viral syndrome).

\section{Presence of risk factors}

The studies included in our systematic review offered limited evidence regarding history of risk factors as a predictor of the underlying cause in acute vestibular syndrome. As described earlier, risk factors for stroke $^{6}$ and perhaps age ${ }^{9}$ have been used in study designs to increase the proportion of patients with acute vestibular syndrome who have stroke, apparently successfully. ${ }^{12}$ Although age is a known risk factor for stroke, evidence from our systematic review showed that stroke should still be considered in younger patients. In the largest prospective study of acute vestibular syndrome, $25 \%(n=15 / 69)$ of patients with ischemic stroke (and 3 of 4 patients with dissection of the vertebral artery identified as the underlying cause) were under 50 years of age. ${ }^{6}$

From our critical review, we found that younger patients with acute vestibular syndrome may be more likely to be misdiagnosed than their older counterparts. In a small series of missed cerebellar infarctions, $50 \%(n=7 / 14)$ of the patients who presented with dizziness were 
under age 50, and all but one of them had dissection or occlusion of the vertebral artery. ${ }^{16}$

In related literature from our critical review, recent head or neck trauma was indicated as a known risk factor for dissection of the vertebral artery (estimated OR 3.8 for minor trauma ${ }^{65}$ ). Because dissection of the vertebral artery is a known cause of acute vestibular syndrome, ${ }^{6}$ a history of trauma should spark concern for underlying dissection. ${ }^{65}$ However, about half of symptomatic dissections occur without an identifiable history of trauma, ${ }^{58}$ so the absence of trauma is insufficient to exclude the diagnosis.

\section{What findings on physical examination are useful for diagnosis?}

Various findings on clinical examination and results of specific tests have been used to distinguish between peripheral and central causes of acute vestibular syndrome.

\section{Neurologic findings}

The presence of general neurologic findings has occasionally been touted by authors as a key feature distinguishing peripheral and central causes of acute vestibular syndrome..$^{81,82}$ The true prevalence of focal neurologic signs in patients with acute vestibular syndrome is difficult to estimate, because symptoms or signs suggesting a central disorder influence patient selection in most studies.

In our systematic review, we identified seven case series that reported focal neurologic signs in stroke patients who presented with acute dizziness. ${ }^{6,26-28,31-33}$ In aggregate, focal neurologic signs were present in $80 \%(n=185 / 230)$, but diagnostic ascertainment bias in patients with obvious neurologic signs likely makes this proportion a substantial overestimate.

The best available data were found in a large prospective study involving patients with acute vestibular syndrome $(n=101) .{ }^{6}$ Obvious general neurologic (e.g., facial palsy, sensory loss, limb ataxia, hemiparesis) or oculomotor (e.g., internuclear ophthalmoplegia, gaze palsy, vertical nystagmus) signs were reported in $51 \%$ of 76 patients with a central cause of acute vestibular syndrome, as compared with none of 25 patients with a peripheral cause. ${ }^{6}$ Some of these signs are not considered "focal" and may not be obvious clinical findings to non-neurologists (e.g., severe as opposed to moderate truncal ataxia; nystagmus with a predominantly vertical or torsional vector, as opposed to a horizontal vector). Symptoms and signs of stroke in the posterior circulation are generally underappreciated by patients, ${ }^{87}$ physicians ${ }^{64}$ and even standardized stroke rating scales. ${ }^{88}$

\section{Imbalance and gait unsteadiness}

Some experts suggest that severe difficulty walking or inability to sit or stand unaided is a sign of central pathology in acute vestibular syndrome. ${ }^{22,89}$ This assertion is supported by some evidence from both our systematic and critical reviews.

In the large prospective study mentioned earlier, severe truncal ataxia (inability to sit with arms crossed unaided) was the only "obvious" neurologic sign in $29 \%$ of patients with stroke and was more frequent among patients with stroke than among those with vestibular neuritis $(33 \% \mathrm{v}$. $0 \%, p<0.001) .{ }^{6}$ A retrospective, populationbased study (not reporting the duration of dizziness) showed that imbalance and gait unsteadiness as part of the presenting complaint was associated with stroke in patients with acute dizziness (OR $3.71,95 \%$ CI $1.30-10.65) .{ }^{15}$ Our systematic review identified one other study in which a large proportion of patients with acute vestibular syndrome of cerebrovascular origin had severe imbalance $(71 \%, n=17 / 24){ }^{10}$ These results generally support those of several other studies of acute vestibular syndrome due to central causes identified in our critical review; in aggregate, gait unsteadiness was reported in $55 \%$ of patients $(n=$ 185/334)..$^{52,78,80,90}$ It remains unknown whether diagnostic ascertainment bias might have played a role in these apparently high frequencies.

\section{Neuro-otologic findings}

The 10 studies in our systematic review focused largely on bedside tests of vestibular and oculomotor function, as assessed through careful examination of eye movements (links to videos of various tests of vestibular and oculomotor function in healthy volunteers and patients with vestibulopathies are provided in Appendix 2).

\section{Spontaneous nystagmus}

Experts suggest that the vector, pattern and fixation characteristics of spontaneous nystagmus can help distinguish peripheral from central causes of acute vestibular syndrome. ${ }^{5,91}$ In our systematic and critical reviews, we found no substantive evidence to support or refute these assertions. Further studies comparing characteristics of spontaneous nystagmus (and bedside means to assess them, such as Frenzel goggles ${ }^{92}$ or the penlight cover test $\mathrm{t}^{91}$ ) in patients with acute vestibular syndrome are needed to determine their diagnostic utility in this context. We also found insufficient data to evaluate the usefulness of examining smooth-pursuit eye movements, saccades and optokinetic nystagmus. 
Vestibulo-ocular reflex

A normal result of the horizontal head impulse test of vestibulo-ocular reflex function ${ }^{93}$ was the single best bedside predictor of peripheral versus central causes of acute vestibular syndrome (Table 4). In the large prospective study described earlier, the head impulse test had a sensitivity for detecting stroke that essentially matched that of diffusion-weighted magnetic resonance imaging (MRI), with both tests having comparable specificity. ${ }^{6}$ In acute vestibular syndrome, an abnormal result of a head impulse test usually indicates a peripheral vestibular lesion, whereas a normal response virtually confirms a stroke. ${ }^{12}$

A normal response to the head impulse test is almost a perfect predictor of stroke when considering the more common infarctions of the posterior inferior cerebellar artery, which generally affect only the cerebellum or lateral medulla, sparing the structures required for an intact vestibulo-ocular response as assessed by the head impulse test. ${ }^{6,22}$

Our systematic review showed, however, that about $15 \%$ of patients with stroke or another central cause of acute vestibular syndrome might be mistakenly considered to have vestibular neuritis, because of an abnormal response to the head impulse test, if no other eye findings are considered. On the basis of known anatomic considerations, we anticipated that the sensitivity of the head impulse test for detecting stroke would vary depending on the specific vascular territory of the posterior circulation involved. Prospectively defined subgroup analysis by vascular territory involved (Table 4) showed that a misleading result of the head impulse test (i.e., abnormal impulse, suggesting a peripheral vestibular lesion, despite stroke as the underlying cause) is almost exclusively associated with infarctions involving the territory of the anterior inferior cerebellar artery. Because this vascular bed includes distal feeding branches to the inner ear, such infarctions often result in a combined ischemic lesion of the lateral pons, inferior cerebellum, labyrinth and chochlea.

A stroke in the labyrinth is technically a peripheral lesion, but it is not benign, particularly when its underlying cause is a severe stenosis of the basilar artery near the origin of the anterior inferior cerebellar artery. Because such a lesion damages the vestibulo-ocular reflex circuit directly, it closely mimics the eye findings of vestibular neuritis, including an abnormal response to the head impulse test. When this occurs, the first clue to the dangerous nature of the disease may be the presence of an associated new, unilateral hearing loss from cochlear involvement, although this is not invariably present. ${ }^{22,23}$ Other subtle oculomotor signs (direction-changing horizontal nystagmus or skew deviation, described below) should also be present when the brainstem or cerebellum is affected.

Table 4: Pooled analysis of key bedside diagnostic predictors of stroke in patients with acute vestibular syndrome*

\begin{tabular}{|c|c|c|c|c|c|c|}
\hline $\begin{array}{l}\text { Bedside diagnostic } \\
\text { predictor* }\end{array}$ & $\begin{array}{l}\text { No. of studies } \\
\text { reporting data on } \\
\text { total/peripheral/ } \\
\text { central causes }\end{array}$ & $\begin{array}{l}\text { No. of patients, } \\
\text { with peripheral/ } \\
\text { central causes }\end{array}$ & $\begin{array}{l}\text { Sensitivity } \\
(95 \% \mathrm{Cl})\end{array}$ & $\begin{array}{l}\text { Specificity } \\
(95 \% \mathrm{Cl}+)\end{array}$ & $\begin{array}{c}\text { Negative } \\
\text { likelihood ratio } \\
(95 \% \mathrm{Cl}+)\end{array}$ & $\begin{array}{l}\text { Positive likelihood } \\
\text { ratio }(95 \% \mathrm{Cl} \text { ) }\end{array}$ \\
\hline \multicolumn{7}{|l|}{$\begin{array}{l}\text { Normal result of } \\
\text { horizontal head } \\
\text { impulse test }\end{array}$} \\
\hline $\begin{array}{l}\text { All central } \\
\text { causes }^{6,10,11,33}\end{array}$ & $4 / 2 / 4$ & $65 / 152 \S$ & $0.85(0.79-0.91)$ & $0.95(0.90-1.00)$ & $0.16(0.11-0.23)$ & $18.39(6.08-55.64)$ \\
\hline $\begin{array}{l}\text { PICA or SCA } \\
\text { stroke }^{6,10,33}\end{array}$ & $3 / 1 / 3$ & $\begin{array}{l}25 / 72 \\
(68 \text { PICA) }\end{array}$ & $0.99(0.96-1.00)$ & $-* *$ & $0.01(0.00-0.10)$ & $-* *$ \\
\hline AICA stroke & $2 / 1 / 2$ & $25 / 13$ & $0.62(0.35-0.88)$ & $-* *$ & $0.40(0.20-0.80)$ & $-* *$ \\
\hline $\begin{array}{l}\text { Direction-changing } \\
\text { nystagmus } \mp^{6,9-11,27,28}\end{array}$ & $6 / 3 / 6$ & 83/239§ & $0.38(0.32-0.44)$ & $0.92(0.86-0.98)$ & $0.68(0.60-0.76)$ & $4.51(2.18-9.34)$ \\
\hline Skew deviation ${ }^{6,11}$ & $2 / 2 / 2$ & $65 / 119 \S$ & $0.30(0.22-0.39)$ & $0.98(0.95-1.00)$ & $0.71(0.63-0.80)$ & $19.66(2.76-140.15)$ \\
\hline \multicolumn{7}{|c|}{$\begin{array}{l}\text { Note: AICA = anterior inferior cerebellar artery, } \mathrm{Cl}=\text { confidence interval, } \mathrm{PICA}=\text { posterior inferior cerebellar artery, SCA = superior cerebellar artery. } \\
\text { * Only studies with an adequate (medium-quality) or superior (high-quality) reference standard for stroke diagnosis were considered. This table includes all } \\
\text { bedside tests used in at least two studies that provided data for either peripheral or central causes of acute vestibular syndrome. Bedside examination of smooth- } \\
\text { pursuit eye movements, optokinetic nystagmus, saccades, positional nystagmus, head-shaking nystagmus, vibration-induced nystagmus and hearing loss are not } \\
\text { shown because of insufficient study numbers }(<2) \text { to offer pooled results. } \\
\text { tCalculated by the method described by Simel et al. } \\
\text { method } \text { were assigned a value of } 1.0 \text {. } \\
\text { fData based on bedside clinical findings and electro-oculography were pooled for these estimates because not all of the studies reported separate results for the } \\
\text { two methods of determining nystagmus. } \\
\text { SIncludes } 27 \text { patients with central causes other than ischemic stroke ( } 14 \text { with demyelination; } 5 \text { with brainstem or cerebellar hemorrhage; } 8 \text { with other causes). } \\
\text { **Pooled specificity is not calculated for this subset of patients with stroke because only one study reporting stroke location also included patients with peripheral } \\
\text { causes. Specificity of a normal result of the head impulse test for predicting stroke should not differ based on stroke location. }\end{array}$} \\
\hline
\end{tabular}


As mentioned earlier, a normal response to the head impulse test in acute vestibular syndrome virtually confirms a stroke. A misleading result of the head impuse test (i.e., abnormal impulse, suggesting a peripheral vestibular lesion, despite stroke as the underlying cause) is uncommon. In this situation, other findings may point to stroke, including the presence of new, unilateral hearing loss or other subtle oculomotor signs.

\section{Gaze-evoked nystagmus}

Another demonstrated bedside predictor of a central cause of acute vestibular syndrome is direction-changing horizontal nystagmus on lateral gaze (i.e., right-beating nystagmus in right gaze and left-beating nystagmus in left gaze, with or without nystagmus when the patient looks straight ahead). ${ }^{5}$ This type of nystagmus generally reflects dysfunction of gaze-holding structures located in the brainstem and cerebellum. ${ }^{94}$ Direction-changing horizontal nystagmus was reported in 6 of the 10 studies in our systematic review and correctly identified central causes with high specificity $(92 \%)$ but low sensitivity (38\%) (Table 4).

\section{Ocular alignment}

Vertical ocular misalignment of vestibular causation ("skew deviation" or "skew") during the alternate cover test was found to be a third bedside predictor for central origins of acute vestibular syndrome. Skew deviation results from a right-left imbalance in otolith and graviceptive inputs from the vestibular system to the oculomotor system and, with rare exceptions, is generally central in origin. ${ }^{95}$ Skew deviation was reported in two of the studies included in our systematic review and, similar to direction-changing nystagmus, correctly identified central causes of acute vestibular syndrome with high specificity (98\%) but low sensitivity (30\%) (Table 4).

\section{Composite HINTS examination}

We identified only one study in our systematic review that directly tested the combination of the three bedside oculomotor findings described earlier in this section, which the authors called HINTS (horizontal head impulse test, nystagmus and test of skew). ${ }^{6}$ According to the authors who described this battery of tests, the composite HINTS examination can be performed in about one minute at the bedside. ${ }^{6}$

Test results that predicted stroke using the HINTS battery of tests were labelled using a second acronym: INFARCT (impulse normal or fast-phase alternating or refixation on cover test). This clinical prediction rule was developed based on neuroanatomic and physiologic princi- ples combined with empiric analysis of results from the first 43 of 101 patients with acute vestibular syndrome in the study ${ }^{6}$ as well as other published literature on acute vestibular syndrome $^{22}$ before it was validated on the next 58 patients. The authors found that the presence of any one of the three dangerous signs had a sensitivity of $100 \%(n=76 / 76)$ and a specificity of 96\% ( $n=24 / 25)$ for stroke (negative likelihood ratio $0.00,95 \% \mathrm{CI} 0.00-0.12$ ); they found that the HINTS battery of tests was better than diffusion-weighted MRI in urgently ruling out stroke in patients with acute vestibular syndrome.

Although not originally reported as a threecomponent battery of tests, results from an earlier, independent study of the three tests constituting HINTS ${ }^{11}$ were later published in a critical review of the diagnosis of cerebellar stroke (sensitivity $91 \%[n=21 / 23]$, specificity $78 \%[n=$ 31/40]). ${ }^{22}$ This earlier study did not repeat MRI scans in patients with clinically diagnosed vestibular neuritis to capture any false-negative results of previous MRIs, which probably led to some underestimation of the specificity of the HINTS tests. Risk of diagnostic misclassification notwithstanding, the pooled sensitivity (98\%), specificity $(85 \%)$ and negative likelihood ratio (0.02, 95\% CI 0.01-0.09) of HINTS for detecting stroke still suggest that bedside eye examination outperforms diffusion-weighted MRI in ruling out stroke in early presentations of acute vestibular syndrome.

\section{Other neuro-otologic tests}

As alluded to earlier, experts agree that specific provocative tests such as the Dix-Hallpike positional test (also known as the Nylén-Bárány manoeuvre) are crucial in the evaluation of patients with transient dizziness to elicit symptoms (i.e., dizziness) and signs (i.e., nystagmus). ${ }^{789} \mathrm{How}-$ ever, such tests are generally unhelpful for diagnosis in patients with acute vestibular syndrome because they fail to differentiate between central and peripheral causes. ${ }^{55,89}$ Other forms of provocative testing to elicit nystagmus for diagnostic purposes (e.g., mastoid vibration, the Valsalva manoeuvre and head shaking ${ }^{92}$ ) have also been described for use in patients with transient, mild or residual symptoms, but they have not been sufficiently studied as diagnostic predictors of underlying cause.

Based on evidence of frequent misdiagnosis and misconceptions in patients presenting with acute dizziness, ${ }^{15,16,18,20,55,96,97}$ it seems prudent to recommend that none of these provocative manoeuvres, including the Dix-Hallpike test, be routinely applied to patients with acute vestibular syndrome in the acute care setting. Both physiologic and 
empiric evidence indicates that provocative testing will lead to a nonspecific worsening of symptoms, which could be misinterpreted as diagnostic of a peripheral vestibular disorder ${ }^{18,20}$ before stroke has been adequately excluded.

\section{What role does laboratory-based audiovestibular testing play in diagnosis?}

Although not the primary focus of our systematic search, we identified several studies of laboratory-based audiovestibular function tests applied in patients with acute dizziness. These tests included pure-tone audiometry, auditory evoked potentials, and various oculomotorvestibular metrics using quantitative electrooculography (Appendix 3). In aggregate, there was insufficient evidence to support the routine use of any of these tests as a means to distinguish peripheral from central causes of acute vestibular syndrome.

\section{What role does neuroimaging play in diagnosis?}

None of the studies involving patients presenting with acute vestibular syndrome of unknown cause compared different neuroimaging modalities. Our critical review showed that, although computed tomography (CT) remains the predominant form of neuroimaging for patients who present to the emergency department with dizziness, ${ }^{2}$ substantial evidence suggests that this approach is grossly inadequate..$^{22}$ In a prospective, blind comparison by expert readers of noncontrast $\mathrm{CT}$ and MRI (with diffusion-weighted and susceptibility weighted images) in a consecutive series of patients referred for emergency assessment of suspected acute stroke, CT had a sensitivity of only $16 \%$ for the diagnosis of acute ischemic stroke, as compared with $83 \%$ for diffusion-weighted MRI, despite the fact that MRI was performed first $85 \%$ of the time..$^{98}$ Imaging in acute vestibular syndrome must assess acute lesions in the posterior fossa, a region where CT performs particularly poorly because of bone-related artifacts. ${ }^{99}$ Although noncontrast CT identified acute intracranial hemorrhage with high sensitivity in the prospective blind comparison, ${ }^{98}$ hemorrhage is an infrequent cause. Among central causes of acute vestibular syndrome, hemorrhage accounts for only about $4 \%$ (Table 2). Not surprisingly, $\mathrm{CT}$ has been shown to have a low diagnostic yield in the assessment of dizziness in patients presenting to the emergency department. ${ }^{100,101}$
Although frequently viewed as the "gold standard" and final arbiter for the diagnosis of stroke, diffusion-weighted MRI can be misleading up to at least 48 hours after symptom onset in patients with acute vestibular syndrome due to ischemic stroke. ${ }^{6}$ Our systematic review found only one study in which patients with an initially negative MRI but evolving signs suggestive of a central cause underwent repeat MRI; falsenegative results were confirmed by delayed MRI in $12 \%(n=8 / 69) .{ }^{6}$ Combining this value with figures reported in two prior studies of diffusionweighted MRI in patients with acute vertebrobasilar stroke from our critical review (falsenegative results in $23 \%, n=47 / 206),{ }^{102,103}$ we estimated the aggregate sensitivity of diffusionweighted MRI of the posterior fossa in the first 24 hours or so after symptom onset to be $80 \%$ $(n=220 / 275)$. Taking an aggregate specificity of 97\% for MRI from the two studies reporting on patients without stroke $(n=198 / 205)$, ${ }^{6.98}$ we estimated a negative likelihood ratio of 0.21 (95\% CI 0.16-0.26), which makes MRI less potent for ruling out stroke than the composite HINTS examination described earlier.

\section{What if the diagnosis of stroke is missed?}

Although details of the management and treatment of acute vestibular syndrome are beyond the scope of this review and are considered in detail elsewhere, ${ }^{22,104}$ a brief discussion of prognosis and the relevance of diagnostic failure based on our critical review is warranted.

Patients whose acute vestibular syndrome is due to a central cause are at risk of additional strokes and secondary complications of the initial stroke, particularly ischemic swelling following large cerebellar infarction. Ischemic stroke of the cerebellum ${ }^{105}$ and cerebellar hemorrhage ${ }^{106}$ can be fatal without close monitoring and urgent neurosurgical intervention at the time of clinical deterioration. A critical review of diagnosis and initial management of cerebellar stroke showed that $10 \%-20 \%$ of patients deteriorate in the days following the event and that swelling peaks on the third day after infarction..$^{22}$ Thus, patients whose acute vestibular syndrome is mistakenly thought to be due to a peripheral cause may appear to be clinically stable at the time of discharge from the emergency department, yet they may be at risk of complications days later.

Dizziness is the symptom in the emergency department most often linked to missed diagnosis of stroke, ${ }^{96}$ with $35 \%$ of cerebrovascular events in patients with any dizziness (and 44\% in 
those with isolated dizziness) missed at first medical contact. ${ }^{15}$ The impact of these errors on patient health is not entirely known, but available data suggest that patients with a misdiagnosis are at particularly high risk of poor outcomes. The one small series of misdiagnosed cerebellar stroke ( $n=15,14$ of whom presented with dizziness or imbalance) reported that $40 \%(n=6 / 15)$ ended in death, ${ }^{16}$ as compared with $5 \%(n=$ $15 / 282)$ in the largest unselected series of patients with known cerebellar stroke ${ }^{90}(p<0.001$, Fisher exact test). Although the small series of missed diagnoses was potentially biased by patient selection, the difference in outcomes occurred despite the fact that patients with a misdiagnosed infarction presented with milder symptoms (normal alertness in 93\%, $n=14 / 15 ;^{16}$ v. $69 \%[n=195 / 282]^{90}$ of those with cerebellar stroke, $p=0.046$, Fisher exact test). If selection bias were to blame for the poor prognosis among those misdiagnosed, we would have expected initial presentations to have been more severe, since milder presentations are associated with a better prognosis. For example, among the 282 patients with a cerebellar infarction, $2 \%$ of those who were alert on presentation became bedridden, vegetative or died, as compared with $13 \%$ of those who were confused and $57 \%$ of those who were obtunded or comatose $(p<0.001$, Cochran-Armitage trend test). ${ }^{90}$

\section{Limitations}

We found only a limited number of rigorously designed studies that prospectively assessed acute vestibular syndrome, including only one that used superior reference standards both to rule in and rule out stroke. ${ }^{6}$ Variability in diagnostic reference standards across studies was a limitation, although the studies used in the analysis of key findings of oculomotor examination all used neuroimaging to diagnose or exclude stroke and met or exceeded an acceptable level of quality of diagnostic reference standard. The dearth of studies with superior reference standards (especially to rule out stroke) means that diagnostic misclassification may still have partially confounded our results.

The bedside tests investigated varied across studies, with relatively small numbers of patients sampled for each test. The highest-quality studies involved patients at higher risk of a vascular cause of acute vestibular syndrome (e.g., older age or with a history of vascular risk factors), leading to more imprecise estimates of test specificity, despite relatively robust estimates of sensitivity.

Evidence to support the three-component battery of tests (HINTS) was limited to two studies involving a total of only 184 patients. ${ }^{6,11}$ Bedside oculomotor tests were performed by experienced subspecialist neuro-otologists, which might limit the generalizability of these findings. A recent small, prospective study involving patients with acute vestibular syndrome $(n=24,10$ of whom had stroke) counters this argument somewhat. ${ }^{107}$ Investigators found that junior neurology residents with limited formal training could perform these same diagnostic tests with sensitivity $(100 \%, n=$ $10 / 10)$ and specificity $(86 \%, n=12 / 14)$ similar to that reported in our systematic review. Although current best evidence supports this approach and a strong recommendation for use (Table 3), the HINTS battery of tests has not yet been fully validated as a clinical prediction rule, ${ }^{108}$ and the generalizability of these findings to routine clinical practice (particularly with generalist rather than specialist examiners) remains to be confirmed.

Studies reviewed were conducted predominantly in the emergency department or acute inpatient setting. Findings may therefore not be generalizable to nonurgent, ambulatory care settings as a result of case-mix differences in cause or severity of illness. This is most likely to be a concern if patients are seen after the acute phase (> 72 hours after onset of symptoms), when eye movement findings have likely evolved as a result of adaptive neural mechanisms.

\section{Conclusion}

Acute continuous dizziness of more than 24 hours' duration is a common presentation in the emergency department, and potential causes range from benign to deadly. The main differential diagnosis is between vestibular neuritis and ischemic stroke. Although physical examination is more likely to be helpful than history-taking once acute vestibular syndrome is identified, red flags for stroke probably include a history of multiple transient prodromal episodes of dizziness over weeks or months; auditory symptoms; and headache, neck pain or recent trauma.

Best evidence suggests that nearly two-thirds of patients with stroke lack focal neurologic signs that would be readily apparent to a nonneurologist (and one-third lack signs that would be readily apparent to a neurologist). For these patients, a three-component bedside oculomotor examination (HINTS) appears to rule stroke in or out with more accuracy than urgent MRI with diffusion-weighted imaging.

Box 2 provides a fictionalized case example of how bedside diagnostic predictors can be applied in clinical practice.

Although expertise in these bedside techniques may currently be limited to specialists, 


\section{Box 2: Applying bedside diagnostic predictors in clinical practice}

A 45-year-old man presents to the emergency department because of continuous dizziness, nausea, vomiting and unsteady gait that began 18 hours earlier. He prefers to lie motionless. He denies auditory or neurologic symptoms, headache, neck pain or recent trauma. He has no relevant medical or exposure history, including no cerebrovascular or vestibular disorders, no recent or remote ear surgery, and no smoking or other vascular risk factors. He is not taking medications. He has no family history of vestibular disease or recurrent dizziness. While obtaining the patient's history, the emergency physician notes his eyes jerking horizontally. Neither a neurology consultation nor neuroimaging is readily available.

Although only symptomatic for 18 hours so far, the patient will soon probably fit the full clinical picture of acute vestibular syndrome (continuous vertigo lasting more than a day, accompanied by nausea or vomiting, intolerance to head motion, nystagmus and unstable gait). The most likely cause is vestibular neuritis, but more dangerous causes such as cerebellar stroke must be considered. The absence of vascular risk factors and age less than 50 years reduce the patient's risk of vertebrobasilar atherosclerosis, but dissection of the vertebral artery remains a concern even though he has no head or neck pain. There are no auditory symptoms to raise concerns about ischemic disturbance of the inner ear. General neurologic findings are normal, including absence of limb ataxia or dysmetria, which is compatible with a peripheral cause. The patient feels unsteady when standing but is able to sit with arms crossed unaided, which is also compatible with a peripheral lesion. Eye examination reveals direction-fixed, left-beating horizontal nystagmus worse in left gaze, and no skew deviation on alternate cover testing, all compatible with the leading potential diagnosis of vestibular neuritis.

The physician does not perform the Dix-Hallpike manoeuvre, recognizing its lack of diagnostic utility in acute vestibular syndrome. However, she tests the patient's vestibulo-ocular responses using the head impulse test and finds normal responses during rapid head rotation in either direction. The normal response in the setting of acute vestibular syndrome strongly suggests a stroke, despite the lack of other symptoms, signs or risk factors.

The patient is admitted to the neurocritical care unit for close monitoring, pending neuroimaging and stroke consultation. MRI obtained the next morning reveals a large infarction of the left posterior inferior cerebellar artery (an example of such an MRI is shown in Figure 2). A complete search for cerebrovascular risk factors identifies a dissection of the left vertebral artery as the underlying cause of the stroke. The patient is observed in the hospital while antithrombotic agents are started. He is discharged uneventfully after the critical three-day window, during which complications related to swelling are most likely. He makes a complete neurologic recovery, his dissection heals, and he reports having no further strokes at two-year follow-up.

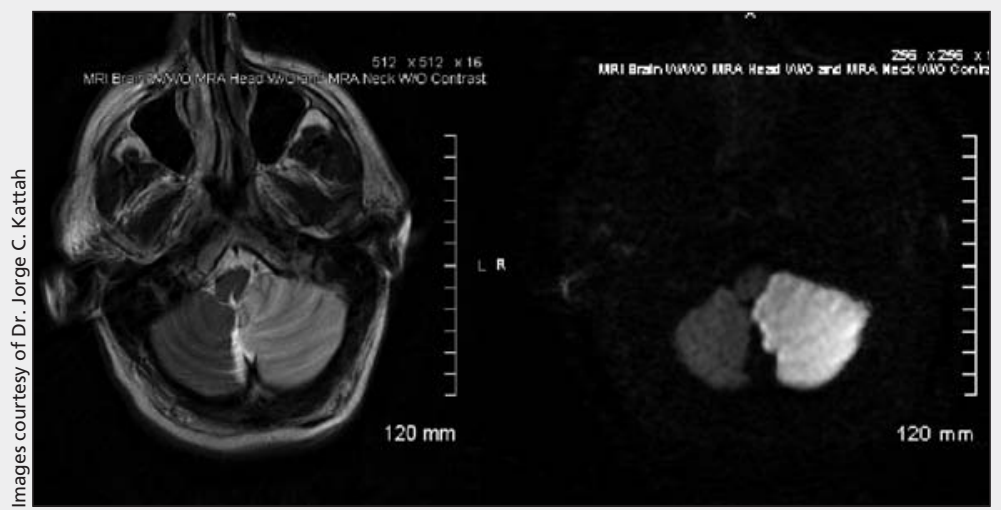

Figure 2: Examples of $T_{2}$-weighted (left) and diffusion-weighted (right) magnetic resonance imaging showing a large left-sided stroke encompassing the territory of the posterior inferior cerebellar artery $\mathbf{2 4}$ hours after the patient presented with acute vestibular syndrome. Initial findings were left-beating horizontal nystagmus, absent skew, but normal response to the horizontal head impulse test, as with the fictionalized case described above. our review suggests that clinical skill development in eye examination is probably warranted for generalists who routinely assess patients with acute dizziness. Training emergency physicians and other frontline physicians in the HINTS examination (or providing a device-based solution such as quantitative video-oculography ${ }^{109}$ ) may be necessary if dangerous causes of acute vestibular syndrome are to be promptly and accurately diagnosed. Negative findings on cranial MRI with diffusion-weighted imaging obtained in the first 48-72 hours after symptom onset should not be considered final in the presence of any dangerous signs from the HINTS tests or a high baseline risk of a vascular cause of acute vestibular syndrome. Future studies should seek to confirm the diagnostic superiority of HINTS in unselected patients with acute vestibular syndrome (with and without auditory symptoms), including the utility of bedside tests when performed by emergency department physicians or other generalists.

\section{References}

1. Kroenke K, Mangelsdorff AD. Common symptoms in ambulatory care: incidence, evaluation, therapy, and outcome. Am J Med 1989;86:262-6.

2. Newman-Toker DE, Hsieh YH, Camargo CA Jr, et al. Spectrum of dizziness visits to US emergency departments: cross-sectional analysis from a nationally representative sample. Mayo Clin Proc 2008;83:765-75.

3. Kruschinski C, Hummers-Pradier E, Newman-Toker D, et al. Diagnosing dizziness in the emergency and primary care settings [letter]. Mayo Clin Proc 2008;83:1297-8.

4. Neuhauser HK, von Brevern M, Radtke A, et al. Epidemiology of vestibular vertigo: a neurotologic survey of the general population. Neurology 2005;65:898-904

5. Hotson JR, Baloh RW. Acute vestibular syndrome. N Engl J Med 1998;339:680-5

6. Kattah JC, Talkad AV, Wang DZ, et al. HINTS to diagnose stroke in the acute vestibular syndrome: three-step bedside oculomotor examination more sensitive than early MRI diffusionweighted imaging. Stroke 2009;40:3504-10.

7. Newman-Toker DE, Camargo CA Jr. "Cardiogenic vertigo" true vertigo as the presenting manifestation of primary cardiac disease. Nat Clin Pract Neurol 2006;2:167-72.

8. Baloh RW. Clinical practice. Vestibular neuritis. $N$ Engl J Med 2003;348:1027-32.

9. Norrving B, Magnusson M, Holtas S. Isolated acute vertigo in the elderly: Vestibular or vascular disease? Acta Neurol Scand 1995;91:43-8

10. Lee H, Sohn SI, Cho YW, et al. Cerebellar infarction presenting isolated vertigo: frequency and vascular topographical patterns. Neurology 2006;67:1178-83.

11. Cnyrim CD, Newman-Toker D, Karch C, et al. Bedside differentiation of vestibular neuritis from central "vestibular pseudoneuritis." J Neurol Neurosurg Psychiatry 2008;79:458-60.

12. Newman-Toker DE, Kattah JC, Alvernia JE, et al. Normal head impulse test differentiates acute cerebellar strokes from vestibular neuritis. Neurology 2008;70:2378-85.

13. Duncan GW, Parker SW, Fisher CM. Acute cerebellar infarction in the PICA territory. Arch Neurol 1975;32:364-8.

14. Kerber KA, Fendrick AM. The evidence base for the evaluation and management of dizziness. J Eval Clin Pract 2010;16:186-91

15. Kerber KA, Brown DL, Lisabeth LD, et al. Stroke among patients with dizziness, vertigo, and imbalance in the emergency department: a population-based study. Stroke 2006;37:2484-7.

16. Savitz SI, Caplan LR, Edlow JA. Pitfalls in the diagnosis of cerebellar infarction. Acad Emerg Med 2007;14:63-8.

17. Newman-Toker DE, Robinson KA, Edlow JA. Frontline misdiagnosis of cerebrovascular events in the era of modern neuroimaging: a systematic review [abstract]. Abstracts of the 133rd Annual Meeting of the American Neurological Association. Ann 
Neurol 2008;64(Suppl 12):S17-8

18. Newman-Toker DE, Camargo CA Jr, Hsieh YH, et al. Disconnect between charted vestibular diagnoses and emergency department management decisions: a cross-sectional analysis from a nationally representative sample. Acad Emerg Med 2009;16:970-7.

19. Kim AS, Fullerton HJ, Johnston SC. Risk of vascular events in emergency department patients discharged home with diagnosis of dizziness or vertigo. Ann Emerg Med. 2011;57:34-41.

20. Stanton VA, Hsieh YH, Camargo CA Jr, et al. Overreliance on symptom quality in diagnosing dizziness: results of a multicenter survey of emergency physicians. Mayo Clin Proc 2007;82. 1319-28.

21. Eagles D, Stiell IG, Clement CM, et al. International survey of emergency physicians' priorities for clinical decision rules. Acad Emerg Med 2008;15:177-82.

22. Edlow JA, Newman-Toker DE, Savitz SI. Diagnosis and initia management of cerebellar infarction. Lancet Neurol 2008;7:951-64.

23. Lee H. Neuro-otological aspects of cerebellar stroke syndrome. J Clin Neurol 2009;5:65-73.

24. Newman-Toker DE. Diagnosing dizziness in the emergency department - why "What do you mean by 'dizzy'?" should not be the first question you ask [doctoral dissertation, Bloomberg School of Public Health]. Baltimore (MD): The Johns Hopkins University; 2007. Available: http://gateway.proquest.com /openurl?url_ver=Z39.88-2004\&res_dat=xri:pqdiss\&rft_val_fmt =info:ofi/fmt:kev:mtx:dissertation\&rft_dat=xri:pqdiss:3267879 [publication no. AAT 3267879] (accessed 2010 Nov. 19).

25. Simel DL, Samsa GP, Matchar DB. Likelihood ratios with confidence: sample size estimation for diagnostic test studies. J Clin Epidemiol 1991:44:763-70.

26. Lee H, Baloh RW. Sudden deafness in vertebrobasilar ischemia: clinical features, vascular topographical patterns and long-term outcome. J Neurol Sci 2005;228:99-104.

27. Lee H, Kim JS, Chung EJ, et al. Infarction in the territory of anterior inferior cerebellar artery: spectrum of audiovestibular loss. Stroke 2009:40:3745-51.

28. Rubenstein RL, Norman DM, Schindler RA, et al. Cerebellar infarction - a presentation of vertigo. Laryngoscope 1980;90: 505-14.

29. Magnusson M, Norrving B. Cerebellar infarctions as the cause of "vestibular neuritis." Acta Otolaryngol Suppl 1991;481:258-9.

30. Magnusson M, Norrving B. Cerebellar infarctions and "vestibular neuritis." Acta Otolaryngol Suppl 1993;503:64-6.

31. Kim GW, Heo JH. Vertigo of cerebrovascular origin proven by CT scan or MRI: pitfalls in clinical differentiation from vertigo of aural origin. Yonsei Med J 1996;37:47-51.

32. Chen $\mathrm{CH}$, Young YH. Vestibular evoked myogenic potentials in brainstem stroke. Laryngoscope 2003;113:990-3.

33. Moon IS, Kim JS, Choi KD, et al. Isolated nodular infarction. Stroke 2009;40:487-91.

34. Lee H, Sohn SI, Jung DK, et al. Sudden deafness and anterior inferior cerebellar artery infarction. Stroke 2002;33:2807-12.

35. Lee H, Cho YW. Auditory disturbance as a prodrome of anterior inferior cerebellar artery infarction. J Neurol Neurosurg Psychiatry 2003;74:1644-8.

36. Neuhauser HK, Lempert T. Vertigo: epidemiologic aspects. Semin Neurol 2009;29:473-81.

37. Newman-Toker DE, Cannon LM, Stofferahn ME, et al. Imprecision in patient reports of dizziness symptom quality: a crosssectional study conducted in an acute care setting. Mayo Clin Proc 2007;82:1329-40.

38. Choi KD, Oh SY, Kim HJ, et al. The vestibulo-ocular reflexes during head impulse in Wernicke's encephalopathy. J Neurol Neurosurg Psychiatry 2007;78:1161-2.

39. Leskinen K, Jero J. Acute complications of otitis media in adults. Clin Otolaryngol 2005;30:511-6.

40. Smiatacz T, Kowalik MM, Hlebowicz M. Prolonged dysphagia due to Listeria-rhombencephalitis with brainstem abscess and acute polyradiculoneuritis. I Infect 2006;52:e165-7.

41. Lin HC, Chao PZ, Lee HC. Sudden sensorineural hearing loss increases the risk of stroke: a 5-year follow-up study. Stroke 2008;39:2744-8.

42. Anagnostou E, Spengos K, Vassilopoulou S, et al. Incidence of rotational vertigo in supratentorial stroke: A prospective analysis of 112 consecutive patients. J Neurol Sci 2010;290:33-6.

43. Naganuma M, Inatomi Y, Yonehara T, et al. Rotational vertigo associated with parietal cortical infarction. J Neurol Sci 2006; 246:159-61.

44. Brandt T, Botzel K, Yousry T, et al. Rotational vertigo in embolic stroke of the vestibular and auditory cortices. Neurology 1995;45:42-4

45. Lloyd-Jones D, Adams RJ, Brown TM, et al. Heart disease and stroke statistics - 2010 update. A report from the American Heart Association. Circulation 2010;121:e46-e215.
46. Baptista MV, van Melle G, Bogousslavsky J. Prediction of inhospital mortality after first-ever stroke: the Lausanne Stroke Registry. J Neurol Sci 1999;166:107-14.

47. Fisher CM. Vertigo in cerebrovascular disease. Arch Otolaryngol 1967;85:529-34.

48. Gomez CR, Cruz-Flores S, Malkoff MD, et al. Isolated vertigo as a manifestation of vertebrobasilar ischemia. Neurology 1996;47:94-7.

49. Grad A, Baloh RW. Vertigo of vascular origin. Clinical and electronystagmographic features in 84 cases. Arch Neurol 1989; 46:281-4.

50. Lee H, Kim BK, Park HJ, et al. Prodromal dizziness in vestibular neuritis: frequency and clinical implication. J Neurol Neurosurg Psychiatry 2009;80:355-6.

51. Silvoniemi P. Vestibular neuronitis. An otoneurological evaluation. Acta Otolaryngol Suppl 1988;453:1-72.

52. Kase CS, Norrving B, Levine SR, et al. Cerebellar infarction. Clinical and anatomic observations in 66 cases. Stroke 1993;24: 76-83.

53. Neuhauser H, Leopold M, von Brevern M, et al. The interrelations of migraine, vertigo, and migrainous vertigo. Neurology 2001;56:436-41

54. Dieterich M, Brandt T. Episodic vertigo related to migraine (90 cases): Vestibular migraine? J Neurol 1999;246:883-92.

55. Newman-Toker DE, Stanton VA, Hsieh YH, et al. Frontline providers harbor misconceptions about the bedside evaluation of dizzy patients [research letter]. Acta Otolaryngol 2008;128:601-4.

56. Gottesman RF, Sharma P, Robinson KA, et al. Imaging characteristics of vertebral artery dissection: a systematic review [abstract]. San Francisco (CA): 135th Annual Meeting of the American Neurological Association; Sept. 2010.

57. de Bray JM, Penisson-Besnier I, Dubas F, et al. Extracranial and intracranial vertebrobasilar dissections: diagnosis and prognosis. J Neurol Neurosurg Psychiatry 1997;63:46-51.

58. Saeed AB, Shuaib A, Al-Sulaiti G, et al. Vertebral artery dissection: warning symptoms, clinical features and prognosis in 26 patients. Can J Neurol Sci 2000;27:292-6.

59. Silbert PL, Mokri B, Schievink WI. Headache and neck pain in spontaneous internal carotid and vertebral artery dissections. Neurology 1995;45:1517-22.

60. Sturzenegger M. Headache and neck pain: the warning symptoms of vertebral artery dissection. Headache 1994;34:187-93.

61. Sturzenegger M, Mattle HP, Rivoir A, et al. Ultrasound findings in spontaneous extracranial vertebral artery dissection. Stroke 1993;24:1910-21.

62. Bartels E. Dissection of the extracranial vertebral artery: clinical findings and early noninvasive diagnosis in 24 patients. $J$ Neuroimaging 2006;16:24-33.

63. Schlaeger R, Naegelin Y, Welge-Lussen A, et al. Acute vertigo with double vision: Brainstem stroke or stroke mimic? Cerebrovasc Dis 2010;30:626-7.

64. Kuruvilla A, Bhattacharya P, Rajamani K, et al. Factors associated with misdiagnosis of acute stroke in young adults. J Stroke Cerebrovasc Dis 2010 Aug. 17 [Epub ahead of print].

65. Rubinstein SM, Peerdeman SM, van Tulder MW, et al. A systematic review of the risk factors for cervical artery dissection. Stroke 2005;36:1575-80.

66. Levels of evidence and grades of recommendation. Oxford (UK): Oxford Centre for Evidence Based Medicine; 2001. Available: www.cebm.net/index.aspx?o=1025 (accessed 2010 Nov. 16).

67. Wayman DM, Pham HN, Byl FM, et al. Audiological manifestations of Ramsay Hunt syndrome. J Laryngol Otol 1990;104: 104-8.

68. Newman-Toker DE, Reich SG. Wrong-way nystagmus in the AICA syndrome [letter]. Laryngoscope 2008;118:378-9.

69. Schunemann HJ, Oxman AD, Brozek J, et al. Grading quality of evidence and strength of recommendations for diagnostic tests and strategies. BMJ 2008;336:1106-10.

70. Atkins D, Best D, Briss PA, et al. Grading quality of evidence and strength of recommendations. BMJ 2004;328:1490.

71. Guyatt GH, Oxman AD, Kunz R, et al. Going from evidence to recommendations. BMJ 2008;336:1049-51.

72. Drachman DA, Hart CW. An approach to the dizzy patient. Neurology 1972;22:323-34.

73. Delaney KA. Bedside diagnosis of vertigo: value of the history and neurological examination. Acad Emerg Med 2003;10:1388-95.

74. Drachman DA. A 69-year-old man with chronic dizziness. JAMA 1998;280:2111-8.

75. Bisdorff A, Von Brevern M, Lempert T, et al. Classification of vestibular symptoms: towards an international classification of vestibular disorders. J Vestib Res 2009;19:1-13.

76. Newman-Toker DE. Charted records of dizzy patients suggest emergency physicians emphasize symptom quality in diagnostic assessment [research letter]. Ann Emerg Med 2007;50:204-5. 
77. Matsuo T, Sekitani T. Vestibular neuronitis: neurotological findings and progress. ORL J Otorhinolaryngol Relat Spec 1985;47: 199-206.

78. Fisher CM, Picard EH, Polak A, et al. Acute hypertensive cerebellar hemorrhage: diagnosis and surgical treatment. J Nerv Ment Dis 1965;140:38-57.

79. Rothwell PM, Buchan A, Johnston SC. Recent advances in management of transient ischaemic attacks and minor ischaemic strokes. Lancet Neurol 2006;5:323-31.

80. Kubo T, Sakata Y, Sakai S, et al. Clinical observations in the acute phase of cerebellar hemorrhage and infarction. Acta Otolaryngol Suppl 1988;447:81-7.

81. Rosenberg ML, Gizzi M. Neuro-otologic history. Otolaryngol Clin North Am 2000;33:471-82.

82. Derebery MJ. The diagnosis and treatment of dizziness. Med Clin North Am 1999;83:163-77.

83. Drachman DA, Diamond ER, Hart CW. Posturally-evoked vomiting; association with posterior fossa lesions. Ann Otol Rhinol Laryngol 1977;86:97-101.

84. Fisher CM. Vomiting out of proportion to dizziness in ischemic brainstem strokes. Neurology 1996;46:267.

85. Lempert T, Neuhauser H, Daroff RB. Vertigo as a symptom of migraine. Ann N Y Acad Sci 2009;1164:242-51.

86. Kelman L. Pain characteristics of the acute migraine attack. Headache 2006;46:942-53

87. Mandelzweig L, Goldbourt U, Boyko V, et al. Perceptual, social, and behavioral factors associated with delays in seeking medical care in patients with symptoms of acute stroke. Stroke 2006;37:1248-53.

88. Martin-Schild S, Albright KC, Tanksley J, et al. Zero on the NIHSS does not equal the absence of stroke. Ann Emerg Med 2011;57:42-5

89. Baloh RW. Dizziness: neurological emergencies. Neurol Clin 1998;16:305-21.

90. Tohgi H, Takahashi S, Chiba K, et al.; Tohoku Cerebellar Infarction Study Group. Cerebellar infarction. Clinical and neuroimaging analysis in 293 patients. Stroke 1993;24:1697-701.

91. Newman-Toker DE, Sharma P, Chowdhury M, et al. Penlightcover test: a new bedside method to unmask nystagmus. J Neuro Neurosurg Psychiatry 2009;80:900-3.

92. Zee DS, Fletcher WA. Bedside examination. In: Baloh RW, Halmagyi GM, editors. Disorders of the vestibular system. New York (NY): Oxford University Press; 1996. p. 178-90.

93. Halmagyi GM, Curthoys IS. A clinical sign of canal paresis. Arch Neurol 1988;45:737-9.

94. Baier B, Dieterich M. Incidence and anatomy of gaze-evoked nystagmus in patients with cerebellar lesions. Neurology 2011; 76:361-5

95. Brodsky MC, Donahue SP, Vaphiades M, et al. Skew deviation revisited. Surv Ophthalmol 2006;51:105-28.

96. Moulin T, Sablot D, Vidry E, et al. Impact of emergency room neurologists on patient management and outcome. Eur Neurol 2003:50:207-14.

97. Kerber KA, Morgenstern LB, Meurer WJ, et al. Nystagmus assessments documented by emergency physicians in acute dizziness presentations: A target for decision support? Acad Emerg Med. In press.

98. Chalela JA, Kidwell CS, Nentwich LM, et al. Magnetic resonance imaging and computed tomography in emergency assessment of patients with suspected acute stroke: a prospective comparison. Lancet 2007;369:293-8.

99. Simmons Z, Biller J, Adams HP Jr, et al. Cerebellar infarction: comparison of computed tomography and magnetic resonance imaging. Ann Neurol 1986;19:291-3.

100. Wasay M, Dubey N, Bakshi R. Dizziness and yield of emergency head CT scan: Is it cost effective? Emerg Med J 2005;22:312.
101. Kerber KA, Schweigler L, West BT, et al. Value of computed tomography scans in ED dizziness visits: analysis from a nationally representative sample. Am J Emerg Med 2010;28:1030-6.

102. Oppenheim C, Stanescu R, Dormont D, et al. False-negative diffusion-weighted MR findings in acute ischemic stroke. AJNR Am J Neuroradiol 2000;21:1434-40.

103. Marx JJ, Thoemke F, Mika-Gruettner A, et al. Diffusionweighted MRT in vertebrobasilar ischemia. Application, sensitivity, and prognostic value [article in German]. Nervenarzt 2004; 75:341-6.

104. Brandt T, Zwergal A, Strupp M. Medical treatment of vestibular disorders. Expert Opin Pharmacother 2009;10:1537-48.

105. Hornig CR, Rust DS, Busse O, et al. Space-occupying cerebellar infarction. Clinical course and prognosis. Stroke 1994;25:372-4.

106. Heros RC. Cerebellar hemorrhage and infarction. Stroke 1982; 13:106-9.

107. Chen L, Lee W, Chambers BR, et al. Diagnostic accuracy of acute vestibular syndrome at the bedside in a stroke unit. $J \mathrm{Neu}$ rol 2010;258:855-61.

108. Laupacis A, Sekar N, Stiell IG. Clinical prediction rules. A review and suggested modifications of methodological standards. JAMA 1997;277:488-94.

109. MacDougall HG, Weber KP, McGarvie LA, et al. The video head impulse test: diagnostic accuracy in peripheral vestibulopathy. Neurology 2009;73:1134-41.

110. Hausler R, Levine RA. Auditory dysfunction in stroke. Acta Otolaryngol 2000;120:689-703.

111. Schuknecht HF. Pathology of the inner ear. Philadelphia (PA): Lea \& Febiger; 1993.

112. Maire R, Van Melle G. Horizontal vestibulo-ocular reflex dynamics in acute vestibular neuritis and viral labyrinthitis: evidence of otolith-canal interaction. Acta Otolaryngol 2004;124:36-40.

113. Boffi A. Cochlear symptoms and signs in vestibular neuronitis. J Laryngol Otol 1965;79:336-42.

114. Committee on Hearing and Equilibrium guidelines for the diagnosis and evaluation of therapy in Menière's disease. American Academy of Otolaryngology-Head and Neck Foundation, Inc. Otolaryngol Head Neck Surg 1995; 113:181-5.

115. Johnson GD. Medical management of migraine-related dizziness and vertigo. Laryngoscope 1998;108:1-28.

116. Radtke A, Lempert T, Gresty MA, et al. Migraine and Ménière's disease: Is there a link? Neurology 2002;59:1700-4.

Affiliations: From the Departments of Neurology (Tarnutzer, Berkowitz, Newman-Toker), Medicine (Robinson) and Emergency Medicine (Hsieh, Newman-Toker), Johns Hopkins University School of Medicine, Baltimore, MD

Contributors: Alexander Tarnutzer, Aaron Berkowitz and David Newman-Toker conceived of the study and conducted the systematic review of the literature. Karen Robinson executed the literature search. Alexander Tarnutzer abstracted and summarized the results. Alexander Tarnutzer, Yu-Hsiang Hsieh and David Newman-Toker performed the statistical analysis. Alexander Tarnutzer and David Newman-Toker drafted the article. All of the authors revised the manuscript critically for important intellectual content and approved the final version of the manuscript submitted for publication.

Funding: This work was supported in part by a grant from the Agency for Healthcare Research and Quality (grant no. HS017755-01). Alexander Tarnutzer's effort in preparing the manuscript was supported by the Swiss National Science Foundation (grant no. PBZHP3-125519). 


\section{Appendix 1: Detailed search and selection strategy (part 1 of 2)}

The search strategy was designed by a PhD-trained clinical investigator with relevant domain expertise (D.N.T.) and the co-director of the Johns Hopkins Evidence-based Practice Center with extensive experience in systematic reviews (K.A.R.). We searched MEDLINE via PubMed for English-language articles, using the following strategy:

(((dizz* [tiab] OR vertigo[tiab] OR vertigo/etiology[mh] OR dizziness/etiology[mh]) OR acute vestibular syndrome[tiab]) AND (prodrom*[tiab] OR diagnos*[tiab] OR manifestation*[tiab] OR clinical feature*[tiab] OR symptom*[tiab])) AND ((acute peripheral vestibulopathy[tiab] OR labyrin*[tiab] OR vestibular neuritis[tiab] OR vestibular neuronitis[tiab] OR vestibular syndrome[tiab]) OR (cerebrovascular[tiab] OR stroke[tiab] OR transient ischaemic attack[tiab] OR transient ischemic attack[tiab] OR TIA[tiab] OR subarachnoid hemorrhage[tiab] OR subarachnoid haemorrhage[tiab] OR ((central nervous system[tiab] OR CNS[tiab]) AND lesion*[tiab])))NOT (animals[mh] NOT humans[mh])AND eng[la]

Our search was up to date through Dec. 4, 2009. We also performed a manual search of reference lists from eligible articles. Because of resource constraints, we did not seek to identify research abstracts from meeting proceedings or unpublished studies, or from studies not in English. Where appropriate, we attempted to contact authors regarding study details.

Titles and abstracts of all identified articles were screened by two independent reviewers (A.A.T., A.L.B.). Articles were selected using predetermined criteria. Articles were excluded if they lacked original patient data, did not describe symptom data about dizziness, provided no information about diagnostic accuracy for acute central (e.g., stroke) or peripheral (e.g., vestibular neuritis) vestibulopathies, did not evaluate patients in the acute stage of disease, involved patients under age 18 years, or reported on fewer than five subjects.

Full-text versions of articles considered eligible or possibly eligible (i.e., labelled "yes" or "maybe" in the abstract review) were screened by two independent reviewers (A.A.T., A.L.B.). The reviewers identified whether full-text manuscripts were eligible and provided a reason for exclusion. A third reviewer (D.N.T.) verified the eligibility of selected articles and settled any discrepancies in selection status and reasons for exclusion. One unmasked rater (A.A.T.) assessed the strength of the reference standard used (see criteria on page 4) to distinguish between a peripheral and a central cause of acute vestibular syndrome in the included studies; a second unmasked rater (D.N.T.) verified the strength of the reference standard.

Information abstracted from each article included study type, number of patients with vertigo/dizziness, inclusion criteria and study site. For each study, we extracted which diagnostic tests were used in the evaluation of patients with acute dizziness and in what fraction of patients the test results were positive and negative. If a study used data from a diagnostic test as an inclusion criterion or as part of the reference standard for diagnosis, that study was excluded from the analysis for that variable so as to avoid selection or diagnostic inclusion bias. For example, if a study included only patients with vestibular neuritis that had a reduced response in caloric irrigation, then results of caloric irrigation from this study were not considered.

For each bedside and audio-vestibular testing procedure that was used in at least two studies involving patients with either peripheral or central causes of acute vestibular syndrome, we calculated the pooled sensitivity, specificity, positive likelihood ratio and negative likelihood ratio of the test, including the $95 \%$ confidence intervals of the positive and negative likelihood ratios. ${ }^{25}$ No formal tests of heterogeneity were applied, but a prospectively defined subgroup analysis was conducted that compared findings of patients who had an infarction of the posterior inferior cerebellar artery (PICA) with findings of patients with an infarction of the anterior inferior cerebellar artery (AICA). Data were handled in EndNote X (Thomson Reuters, NY) and Microsoft Excel 2007 (Redmond, Wash.). SAS version 9.1 (SAS Institute Inc., Cary, NC) was used to calculate the Cochran-Armitage trend test and $p$ value statistics. All $p$ values were two-sided, with values $<0.05$ considered significant. Sensitivity, specificity, and negative and positive likelihood ratios and their respective $95 \% \mathrm{Cls}$ were calculated with the method described by Simel. ${ }^{25}$

\section{Search results}

Our search identified 779 unique citations, of which 640 were excluded at the abstract level (see Figure 1 of the main article for details in the search strategy). We did not require concordance on reason for abstract exclusion; however, of concordant codings $(52.8 \%, n=338)$, articles were excluded for the following reasons: $1 \%$ were not in English; $29 \%$ lacked original patient data; $13 \%$ did not describe symptom data about dizziness; $15 \%$ provided no information about diagnostic accuracy for acute vestibular syndromes; $9 \%$ did not evaluate patients in the acute stage of their presentation; and $33 \%$ were excluded for reporting on fewer than five patients. 


\section{Appendix 1: Detailed search and selection strategy (part 2 of 2)}

We sought to examine 139 full articles, 3 of which were unretrievable. After initial screening, there were 25 disagreements about study inclusion (kappa value $=0.54$ ), and 9 disagreements about the reason for exclusion (kappa value $=0.84$ ). These were settled by adjudication and discussion with the third reviewer. After final review of the full-text versions, 114 articles were excluded. The most common reason for exclusion was failure to provide information about diagnostic accuracy for acute central or peripheral vestibulopathies $(52 \%, n=59)$; other reasons for exclusion were: patients not evaluated in the acute stage of disease $(31 \%, n=36)$; no symptom data about dizziness were provided $(10 \%, n=11)$; patients aged less than 18 years were included $(5 \%, n=6)$; and fewer than five patients included $(2 \%, n=2)$. A review of the bibliographies of the selected 22 articles identified another 5 articles that met the inclusion criteria. In total, 27 articles reporting data from 21 studies were eligible. Eligible articles represented $3.4 \%$ of the total $(n=784)$ articles. These 27 articles reporting on data from 21 studies involved 1374 patients and described diagnoses in unselected patients with dizziness or subgroups of patients with acute prolonged and persistent dizziness or vertigo presenting to the emergency department ( $n=15$ studies) or to an outpatient clinic $(n=2)$; in 4 studies the site was not reported.

In these 21 studies, the reference standard for ruling in or ruling out stroke was determined (see criteria below). For the systematic review of bedside and audiovestibular diagnostic tests, only studies with a medium- or high-quality reference standard for ruling in or ruling out stroke were included. Ten studies involving a total of 392 patients (reported in 15 published articles) were included in the systematic review.

Criteria used to assess strength of reference standards to rule in or rule out stroke in patients with acute vestibular syndrome (AVS)

\section{Strength of reference standard to rule in acute stroke*}

- High:

o Positive acute ( $<10$ days after symptom onset) cranial MRI with DWI OR

o Negative early acute (0-72 hours after symptom onset) cranial MRI (with or without DWI) plus positive follow-up acute $(<30$ days) cranial MRI, showing evolution between images OR

o Positive cranial CT (unequivocal, stroke-like lesion - e.g., wedge-shaped)

- Medium:

o Positive cranial MRI (not qualifying as "high") OR

o Positive cranial CT (not qualifying as "high")

- Low:

o Other (e.g., clinical diagnosis)

\section{Strength of reference standard to rule out acute stroke (i.e., confirm peripheral cause of AVS)}

- High:

o Negative late acute (72 hours-10 days after symptom onset) cranial MRI with DWI OR

o Negative early acute (0-72 hours after symptom onset) cranial MRI (with or without DWI) plus negative follow-up cranial MRI showing no evolution OR

o Negative early acute (0-72 hours after symptom onset) cranial MRI (with or without DWI) plus clinical follow-up for TIA/stroke of $\geq 3$ months

- Medium:

o Negative acute (< 10 days after symptom onset) cranial MRI (with or without DWI) (not qualifying as "high") OR

o Negative post-acute ( $>10$ days after symptom onset) neuroimage (cranial MRI or CT) plus clinical follow-up for TIA/stroke of $\geq 3$ months

- Low:

o Other (e.g., clinical diagnosis; negative acute CT without follow-up)

Note: $\mathrm{CT}$ = computerized tomography; $\mathrm{DWI}=$ diffusion-weighted imaging; $\mathrm{MRI}=$ magnetic resonance imaging;

$\mathrm{TIA}=$ transient ischemic attack.

*For a lesion identified by neuroimaging to be considered "positive" for acute stroke as a cause of AVS, we defined that it must be located in the brainstem or cerebellum. Cerebral hemispheric lesions, even ones clearly identified as acute (e.g., by abnormal finding on MRI with DWI), were not considered "positive" by this definition. 


\section{Appendix 2: Links to videos showing examination techniques and results of bedside diagnostic predictors of stroke in patients with and without acute vestibular syndrome}

\section{Head impulse test}

- Abnormal result in peripheral vestibulopathy http://stroke.ahajournals.org/content/vol0/issue2009/images/data/STROKEAHA.109.551234 /DC1/Kattah_Video1a_APV_HITabnormal.wmv

- Normal result in central vestibulopathy due to stroke http://stroke.ahajournals.org/content/vol0/issue2009/images/data/STROKEAHA.109.551234 /DC1/Kattah_Video1b_PICAStroke_HITnormal.wmv

\section{Nystagmus}

- Direction-fixed nystagmus in peripheral vestibulopathy http://content.lib.utah.edu/u?/ehsl-dent, 1

- Direction-changing nystagmus in central vestibulopathy due to stroke http://content.lib.utah.edu/u?/ehsl-dent,2

\section{Test of skew}

- Skew deviation in central vestibulopathy due to stroke http://stroke.ahajournals.org/content/vol0/issue2009/images/data/STROKEAHA.109.551234 /DC1/Kattah_Video3_LatMedullaStroke_SkewAltCover.wmv

The following videos can be found on the website of the Neuro-Ophthalmology Virtual Education Library (NOVEL): http://library.med.utah.edu/NOVEL/Newman-Toker/

[Click on the link that says "Collection" then "A. Ocular and neurologic examinations."]

\section{Head impuse-nystagmus-test of skew (HINTS)}

- HINTS three-step battery of tests in a healthy volunteer*

- Close-up of HINTS tests in a healthy volunteer

\section{Vestibulo-ocular reflex (VOR) cancellation}

- VOR cancellation in a healthy volunteer

- Close-up of VOR cancellation in a healthy volunteer

\section{Dix-Hallpike manoeuvre}

- Dix-Hallpike manoeuvre for left posterior semicircular canal in a healthy volunteer

\section{Penlight cover test}

- Penlight cover test in a healthy volunteer

*A narrated description of the HINTS examination with videos of abnormal findings is available at: www.medscape.com/viewarticle/710698.

Videos 1-3 were published in association with:

- Newman-Toker DE, Kattah JC, Alvernia JE, Wang DZ. Normal head impulse test differentiates acute cerebellar strokes from vestibular neuritis. Neurology 2008;70:2378-85. www.neurology.org/cgi/content/full/70/24_Part_2/2378/DC1

- Kattah JC, Talkad AV, Wang DZ, Hsieh YH, Newman-Toker DE. H.I.N.T.S. to diagnose stroke in the acute vestibular syndrome: three-step bedside oculomotor exam more sensitive than early MRI diffusion-weighted imaging. Stroke 2009 Nov;40(11):3504-10. http://stroke.ahajournals.org/cgi/content/full/STROKEAHA.109.551234/DC1 


\section{Appendix 3: Audiometric and vestibular testing in acute vestibular syndrome}

We identified several studies in our systematic review that reported on laboratory-based, physiologic audio-vestibular tests applied in patients presenting with acute dizziness. The tests included pure-tone audiometry, ${ }^{9,10,27,28}$ brainstem auditory evoked potentials, ${ }^{34}$ or electro-oculography to quantify smooth-pursuit eye movements, ${ }^{9,10}$ saccades, ${ }^{10}$ optokinetic nystagmus, ${ }^{10}$ or caloric responses. ${ }^{9,10,26-28,33}$ However, the number of studies reporting on these tests that had a reference standard rated as medium or high quality to rule in or rule out stroke was insufficient to estimate pooled test statistics for predicting central causes of acute vestibular syndrome (AVS).

Hearing loss deserves special consideration. It is generally found in association with inner ear diseases and frequently leads clinicians to diagnose a peripheral cause of AVS, but it can be associated with stroke. ${ }^{110}$ When AVS is accompanied by auditory symptoms and believed to be of peripheral localization, it is sometimes called "neuro-labyrinthitis" or "labyrinthitis" rather than "vestibular neuritis," although this distinction in terminology is inconsistently applied. From an anatomic standpoint, it is appropriate that unilateral hearing loss in patients with dizziness or vertigo usually indicates a peripheral localization, given the known redundancy in central auditory pathways beyond the cochlear nucleus. ${ }^{110}$ However, hearing loss, even if indicative of a peripheral cause of AVS, does not exclude an underlying vascular cause (i.e., infarction of the labyrinth), because the blood supply to the inner ear derives from the posterior cerebral circulation, generally as a distal branch of the anterior inferior cerebellar artery (AICA) (reviewed in Newman-Toker ${ }^{24}$ ).

As part of our critical review, we found that hearing loss in AVS is frequently associated with stroke, despite classic teaching to the contrary. Hearing loss in AICA stroke was noted in about $25 \%(n=3 / 12)$ of patients when tested at the bedside (personal communication with the first author of the largest series of AVS presentations $\left.{ }^{6}\right)$ and in $65 \%(n=52 / 80)$ tested by pure-tone audiometry, ${ }^{27}$ mimicking a benign, peripheral (neuro-)labyrinthitis. ${ }^{111}$ Rigorous, unbiased data on hearing loss in acute peripheral vestibulopathies (whether called "labyrinthitis" or "neuritis") are lacking. One study involving 63 patients with peripheral AVS found hearing loss in 33\%; however, this proportion may be an overestimate because the authors did not state whether it was a consecutive series and the reference standard for excluding stroke as a cause was low. ${ }^{112}$ As is typical in the literature ${ }^{68}$ several studies of vestibular neuritis identified as part of our systematic or critical review excluded patients with hearing loss; ${ }^{11,50,51}$ thus, the prevalence of auditory symptoms in peripheral AVS is probably underestimated. In another study from the pre-imaging era, tinnitus or aural fullness was reported in association with the onset of vestibular symptoms by $31 \%(n=29 / 93)$ of patients with vestibular neuritis, but results of pure-tone audiometry (without speech discrimination testing) were normal in all 29 cases. ${ }^{113}$

Furthermore, none of the AVS studies we reviewed enrolled or reported on patients with Menière disease or vestibular migraine. Hearing loss and tinnitus are common complaints in Menière disease $e^{114}$ and may also occur during episodes of migrainous vertigo. ${ }^{115,116}$ At least some such patients were excluded from AVS studies reported here. ${ }^{6,12}$ Therefore, no firm conclusions can be drawn about the power of hearing loss or abnormal findings of pure-tone audiometry to predict central causes of AVS in a completely unselected AVS population.

Considering the frequent use of caloric irrigation to assess vestibular function in specialized neuro-otology clinics, it is important to briefly discuss its limitations. A reduced response on caloric irrigation was an inclusion criterion in all vestibular neuritis studies identified in the critical review, ${ }^{50,51}$ which makes estimates of the prevalence of abnormal responses on caloric irrigation in vestibular neuritis meaningless. Not surprisingly, reduced responses on caloric irrigation have been noted in patients with AICA territory strokes, presumably due to labyrinthine ischemia via lack of distal blood flow in the labyrinthine artery. ${ }^{10,27}$ However, similar findings have also been seen in a large fraction of AVS patients with posterior cerebellar artery (PICA) territory strokes, ${ }^{12}$ which casts doubt on whether caloric irrigation is specific for a peripheral localization in AVS. These observations mandate caution when interpreting results from caloric irrigation that may be mistakenly assumed to reflect benign peripheral vestibular disease. 